\title{
Modelling Salinity and Sodicity Risks of Long-Term Use of Recycled Water for Irrigation of Horticultural Crops
}

\author{
Vinod Phogat ${ }^{1,2, *}$, Dirk Mallants ${ }^{3} \mathbb{C}^{\text {, Jirka Šimůnek }}{ }^{4} \mathbb{D}^{\text {, James W. } \text { Cox }^{1,2}, \text { Paul R. Petrie }^{1,2,5} \text { and Timothy Pitt }}{ }^{1,2}$ \\ 1 South Australian Research and Development Institute, GPO Box 397, Adelaide, SA 5001, Australia; \\ jim.cox@sa.gov.au (J.W.C.); paul.petrie@sa.gov.au (P.R.P.); tim.pitt@sa.gov.au (T.P.) \\ 2 Faculty of Sciences, School of Agriculture, Food and Wine, University of Adelaide, PMB 1, \\ Glen Osmond, SA 5064, Australia \\ 3 CSIRO Land and Water, PMB 2, Glen Osmond, SA 5064, Australia; dirk.mallants@csiro.au \\ 4 Department of Environmental Sciences, University of California, Riverside, CA 92521, USA; \\ jiri.simunek@ucr.edu \\ 5 School of Mechanical and Manufacturing Engineering, The University of New South Wales, \\ Sydney, NSW 2052, Australia \\ * Correspondence: vinod.phogat@sa.gov.au
}

\section{check for} updates

Citation: Phogat, V.; Mallants, D.; Šimůnek, J.; Cox, J.W.; Petrie, P.R.; Pitt, T. Modelling Salinity and Sodicity Risks of Long-Term Use of Recycled Water for Irrigation of Horticultural Crops. Soil Syst. 2021, 5 , 49. https://doi.org/10.3390/ soilsystems 5030049

Academic Editors:

Thomas Baumgartl and

Mandana Shaygan

Received: 7 June 2021

Accepted: 18 August 2021

Published: 21 August 2021

Publisher's Note: MDPI stays neutral with regard to jurisdictional claims in published maps and institutional affiliations.

Copyright: (c) 2021 by the authors. Licensee MDPI, Basel, Switzerland. This article is an open access article distributed under the terms and conditions of the Creative Commons Attribution (CC BY) license (https:/ / creativecommons.org/licenses/by/ $4.0 /)$.

\begin{abstract}
Long-term use of recycled water (RW) for irrigation in arid and semiarid regions usually changes the soil solution composition and soil exchange characteristics, enhancing the risk for salinity and sodicity hazards in soils. This modelling study focuses on developing alternative management options that can reduce the potentially harmful impacts of RW use on the irrigation of wine grapes and almonds. The multicomponent UNSATCHEM add-on module for HYDRUS-1D was used to evaluate the impact of long-term (2018-2050) use of irrigation waters of different compositions: goodquality low-salinity (175 mg/L) water (GW), recycled water with $1200 \mathrm{mg} / \mathrm{L}$ salinity (RW), blended water of GW and RW in the 1:1 proportion (B), and monthly (Alt1) and half-yearly (Alt6) alternate use of GW and RW. The management options include different levels of annual gypsum applications $(0,1.7,4.3$, and $8.6 \mathrm{t} /$ ha soil) to the calcareous (Cal) and hard red-brown (HRB) soils occurring in the Northern Adelaide Plain (NAP) region, South Australia. Additional management scenarios involve considering different leaching fractions $(\mathrm{LF})(0.2,0.3,0.4$, and 0.5$)$ to reduce the salinity build-up in the soil. A new routine in UNSATCHEM to simulate annual gypsum applications was developed and tested for its applicability for ameliorating irrigation-induced soil sodicity. The 1970-2017 period with GW irrigation was used as a warmup period for the model. The water quality was switched from 2018 onwards to reflect different irrigation water qualities, gypsum applications, and LF levels. The data showed that the GW, B, Alt1, and Alt6 irrigation scenarios resulted in lower soil solution salinity $\left(\mathrm{EC}_{\mathrm{SW}}\right)$ than the RW irrigation scenario, which led to increased $\mathrm{EC}_{\mathrm{SW}}$ values $(4.1-6.6 \mathrm{dS} / \mathrm{m})$ in the soil. Annual gypsum applications of 1.7, 4.3, and 8.6 t/ ha reduced pH, SAR, and ESP in both soils and reduced the adverse impacts of irrigation, especially in surface soils. A combination of water blending or cyclic water use with $3.8 \mathrm{t} /$ ha annual gypsum applications showed promise for the SAR and ESP control. Additionally, irrigation with RW, a $0.2 \mathrm{LF}$, and annual gypsum applications limited the harmful salinity impacts in the soils. However, in the RW irrigation scenario, $\mathrm{EC}_{\mathrm{sw}}$ and ESP at the bottom of the crop root zone (90-120 cm depth) in the HRB soil were still higher than the wine grape and almond salinity thresholds. Thus, annual amendment applications, combined with the long-term use of blended water or cyclic use of RW and GW, represent a sustainable management option for crop production at the calcareous and hard red-brown soils.
\end{abstract}

Keywords: recycled water; UNSATCHEM; gypsum; leaching fraction; calcareous soils; hard redbrown soils; climate change 


\section{Introduction}

Availability of freshwater for irrigation is diminishing worldwide due to a rapid increase in demand by other sectors (e.g., industrial and urban), erratic rainfall distribution, and dwindling surface and groundwater water resources. Therefore, other sources of irrigation water are increasingly being explored to sustain irrigated agriculture. These waters include wastewaters emanating from public utilities and industries. These waters may contain numerous disease-causing organisms, hazardous chemicals, metal ions, and other impurities. Although direct use of these waters is prohibited, post-treated use for irrigation is not uncommon, especially in arid and semiarid regions, including Australia. There is wide-ranging experience using recycled water for irrigation of different crops involving varied soil textures, climate, and management conditions [1,2].

Generally, the use of recycled water (RW) for irrigation can have both positive and negative impacts on crops and soils, depending on the water quality and the extent and duration of exposure. The benefits include reducing freshwater demand, recycling nutrients, minimizing the discharge of pollutants into waterways [3,4], and improving soil fertility, nutrient uptake, plant growth, and crop yield [4-9]. Despite these beneficial impacts, negative influences of long-term use of RW are also common. Therefore, appropriate management of these waters is essential to realize their promise for sustainable use for crop production [10-12].

Sustainable use of treated/recycled water (RW) for irrigation refers to developing strategies and management tools to help reduce harmful impacts at the farm and regional scales while maintaining the soil's productive capacity. The main factor affecting the management of RW irrigation is the interaction between the total mass of salts in the soil, salinity of irrigation water (characterized by electrical conductivity, EC), the ratio of sodium and other cations in the solution (represented by the sodium absorption ratio, SAR), and the fraction of the solid phase occupied by sodium cations (characterized by the exchangeable sodium percentage, ESP) in the soil. In recent years, the role of high concentration of $\mathrm{K}$ and $\mathrm{Mg}$ on the soil exchange and soil solution, typical of recycled municipal wastewater [13], is being reassessed by many researchers. Numerous studies have shown that $\mathrm{Mg}$ can have adverse impacts on the permeability of irrigated soils [14-16]. The magnitude of impacts depends on soil clay mineralogy, as well as on the relative amounts of $\mathrm{K}$ and $\mathrm{Mg}$ over $\mathrm{Na}$ and $\mathrm{Ca}$ in the soil exchange and in irrigation water [14,17-19]. Recognizing the role of $\mathrm{K}$ and $\mathrm{Mg}$, Rengasamy and Marchuk [14] proposed a cation ratio of structural stability (CROSS) alternate to SAR. This average value for the $\mathrm{Mg}$ coefficient is consistent with the value 0.60 utilized by Rengasamy and Sumner [20]. Zhu et al. [18] found that the numerical coefficient for the K concentration in CROSS was in the range of 0.309-0.777, with an average value of 0.605 . These factors control soil salinity, soil structure degradation, water flow, and leaching of soluble salts from the root zone.

Soil salinity impacts plant growth through osmotic and toxicity effects and causes nutrient imbalances in the soil [21,22]. High SARSAR or ESP causes soil sodicity (resulting in soil dispersion/swelling), thus increasing soil resistance and reducing root growth and water movement through the soil [23]. High sodicity reduces the leaching of salts from the root zone and may cause oxygen depletion through waterlogging [24] and restricted drainage conditions in the soil.

The adverse impacts of RW irrigation depend on factors such as the chemical composition of irrigation water, climate parameters, soil texture, vertical soil heterogeneity (e.g., the presence of clay-rich horizons), and the water needs and tolerance levels of crops. However, there is a strong tendency for RW waters to have higher salinity and higher concentrations of sodium ( $\mathrm{Na}$ ) relative to other cations compared to other irrigation waters [25]. To better understand salinity problems, one must realize that every irrigation water adds salts into the soil system. For example, irrigation with $1 \mathrm{ML}$ of good-quality water $(0.5 \mathrm{dS} / \mathrm{m}$, similar to rainwater) can add approximately $320 \mathrm{~kg}$ of salts into the soil. As plants usually contain no more than $3.5 \%$ of salts in the dry matter [26], no more than $350 \mathrm{~kg}$ of salts applied with irrigation water can be exported in $10 \mathrm{t}$ of harvestable products. The salt mass in the 
soil increases with each irrigation unless the salts are leached below the crop rooting zone by an excess of water above what the soil can store [26]. Therefore, a minimum leaching fraction (LF) is required in all irrigation systems, regardless of water quality, to remove the inevitable build-up of salts from the rooting zone [27]. If salts accumulated due to RW irrigation are not properly leached, increased osmotic pressures can potentially lead to a severe reduction in the sap flow and water absorption by the plants $[28,29]$ and ultimately have a drastic impact on crop growth and yield $[2,24]$.

On the other hand, high SAR of irrigation water can have harmful impacts on the soil by increasing the soil's ESPESP, which induces severe soil structural (e.g., crusting) and hydraulic (pore blockage and permeability reduction) problems. RWs typically have SAR values ranging from 7.5 to 8.5 , which can potentially lead to the development of high ESP in the soil $[25,30]$. The soil analysis of the NAP region in the current project also indicated that most soils have high ESP, especially in the subsoil [10]. Other studies have also observed significant ill-effects of long-term irrigation with RW on soils' physicochemical properties [11,12,24,31-33]. Increased ESP causes deterioration of soils' physical properties, such as clay dispersion, with a subsequent collapse of soil structure, pore blockage, and eventually, a decrease in soil permeability, leading to waterlogging, poor plant performance, decreased leaching, and salinization [34-36]. Intensive irrigation with RW of loam and clay soils has been shown to result in a significant increase in clay dispersion and its eluviation from the upper soil layers [37]. Notably, clay dispersion may be greatly increased by high concentrations of $\mathrm{Na}^{+}$in the soil solution due to $\mathrm{Na}^{+}$dominating the soil exchange complex. In addition, the reduced hydraulic conductivity can result in the increased surface runoff of irrigation water, which may then contaminate other water bodies with both dissolved and suspended materials.

Although salt accumulation and sodicity will inevitably increase with irrigation, this development can be slowed down and even reversed within the crop root zone by applying careful management. However, judicious use for irrigation requires developing site-specific management options to mitigate the harmful impacts [38]. To address RW-induced problems and devise site-specific practical guidelines, there is a need to evaluate multiple long-term strategies to reduce expected harmful impacts on the soil while sustaining crop production. If irrigation water salinity is too high for crop growth, dilution with lower salinity water could be a good approach [39].

Grattan and Rhoades [40] advocated alternate irrigation with fresh and saline waters in preference to blending, suggesting that this improves soil conditions by leaching salts with lower salinity water. Experiments with grapevines and saline waters [41,42] showed that irrigation with non-saline water (rainfall) for two months usually returned soil $E C_{e}$ to pre-saline irrigation conditions. Irrigation with fresh or blended water prior to planting is also a useful option since it provides the seedlings, which are more sensitive to salts [43], with a less saline environment during their establishment. This would also reduce leaching requirements during subsequent crop growth [44]. Balancing fresh, saline, and/or reclaimed water irrigation may be valuable for maintaining soil quality under irrigated crops. However, this should be practiced with caution as this can lead to increased soil degradation problems.

On the other hand, to address high SAR- and ESP-related problems, frequent application of Ca (e.g., gypsum/organics) is essential for reducing the harmful impacts of RW with high exchangeable $\mathrm{Na}^{+}$. Gypsum directly affects the flocculation and aggregation of the subsoil and indirectly improves rooting, which leads to greater aggregation [45]. However, the extent and frequency of such amendments depend on continuous changes in the soil solution due to RW irrigation and inherent sodicity problems. Other options include evaluating the impact of blending RW with good-quality water (GW), harvesting stormwater, or using RW and GW alternatively. Thus, appropriate irrigation water use is essential to reduce the adverse impacts of soil salinity and sodicity in the soil system.

This modelling study used the HYDRUS 1D-UNSATCHEM simulator to evaluate the impact of different management scenarios involving long-term irrigation with waters of 
different qualities applied to two texturally different soils and crops with different salt tolerance to sustainably manage water and soil resources. To the best of our knowledge, this is the first time that such a comprehensive set of modelling scenarios has been evaluated, focusing on the impact of annual gypsum applications and leaching fraction to ameliorate the adverse impact of the use of RW water for irrigation. Results will help devise better management strategies for using recycled water in combination with other available water resources.

\section{Materials and Methods}

\subsection{Description of the Study Area}

The study region covers a part of the Northern Adelaide Plains (NAP), South Australia, where a considerable expansion of irrigated horticulture has been initiated, predominantly utilizing available RW from the adjoining Bolivar treatment plant [46]. The wastewater is treated using the "Dissolved Air Flotation and Filtration" (DAFF) technique through a tertiary filtration and disinfection process, making it suitable for irrigating horticultural crops. The NAP has a Mediterranean-type climate characterized by hot, dry summers and cool to cold winters. Long-term (1900-2016) average rainfall in the region amounts to $475 \mathrm{~mm}$ [47], and annual evapotranspiration amounts to $1308 \mathrm{~mm}$. Therefore, horticultural orchards require intensive irrigation for profitable production. A more detailed description of the study area can be found in [10].

Average seasonal RW quality data were estimated from raw data from 2002-2017 [48]. The final values used for the modelling study are taken from Phogat et al. [12]. The water quality falls into the medium category of the salinity rating in Australia [49], which means that moderately tolerant crops can be grown using RW as an irrigation source.

Fourteen representative soil profiles were excavated in the study area to determine the relevant physico-chemical properties of the main soil groups. The sampling strategy was focused on ensuring a reasonable representation of major soil groups occurring in the region. More details about the soil sampling sites are described in [50]. The prominent soil groups occurring in the region are hard red-brown (HRB), deep uniform to gradational $(\mathrm{DuG})$, calcareous (Cal), and sand over clay (SOC) textures covering 52,13,12, and 10\% of the study area, respectively [51]. A number of soil profiles were sampled from each soil group: 6 from HRB, 3 from Cal, 3 from SOC, and 2 from DuG textural groups. Undisturbed (single) and disturbed (triplicate) soil samples were collected from each profile at depths of 0-10, 10-30, and 30-60 cm. Additional samples were collected from greater depths where sampling was not impeded by hard soil layers (60-90 and 90-120 cm). This investigation has put most effort on the calcareous and hard red-brown soil groups, which are the predominant soil groups in the NAP region [51]. Disturbed soil samples were used for particle size analysis, while undisturbed cores were used to measure the bulk density, the water content-matric suction relationship, and the saturated hydraulic conductivity [52]. More details on measuring soil hydraulic and soil chemical properties can be found in Appendix A.

\subsection{Modelling Scenarios}

We used the UNSATCHEM module of HYDRUS-1D [53] to evaluate the long-term dynamics of coupled water flow, solute transport, and major ion geochemistry in the predominant soils in the NAP region under different applications of irrigation water quality and soil amendments [10]. Few studies have evaluated the impact of the long-term use of RW on soil properties and crop yield [12,54]. This study mainly focuses on managing the long-term use of RW, utilizing scarce GW, and their various alternate and blending combinations. The blending mode consists of 1:1 mixing of RW and GW (B), and the RW and GW alternate use comprises monthly (Alt1) and half-yearly cycles (Alt6). The scenarios with different annual gypsum applications of $0,1.7,4.3,8.6$, and $12.9 \mathrm{t} /$ ha are designated as G0, G1, G2, G3, and G4, respectively. The various leaching fraction scenarios (LF = 0.2, 0.3, 0.4 , and 0.5) are listed as LF0.2, LF0.3, LF0.4, and LF0.5, respectively. The LF0.2 scenario 
was adopted as a base scenario for different irrigation application modes. Wine grapes and almonds were considered as test crops in the calcareous and hard red-brown soils, respectively. Detailed information on individual scenarios for different NAP soils is given in Tables 1 and 2.

Table 1. Different water quality and gypsum application scenarios performed for the calcareous soil (Cal) under wine grapes.

\begin{tabular}{cccccc}
\hline Scenario No. & $\begin{array}{c}\text { Water } \\
\text { Quality }\end{array}$ & $\begin{array}{c}\text { Gypsum } \\
\text { Application } \\
\text { (t/ha) }\end{array}$ & Scenario No. & $\begin{array}{c}\text { Water } \\
\text { Quality }\end{array}$ & $\begin{array}{c}\text { Gypsum } \\
\text { Application } \\
\text { (t/ha) }\end{array}$ \\
\hline 1 & RW & 0 & 14 & Alt1 & 1.72 \\
2 & RW & 1.72 & 15 & Alt1 & 4.3 \\
3 & RW & 4.3 & 16 & Alt1 & 8.6 \\
4 & RW & 8.6 & 17 & Alt6 & 0 \\
5 & GW & 0 & 18 & Alt6 & 1.72 \\
6 & GW & 1.72 & 19 & Alt6 & 4.3 \\
7 & GW & 4.3 & 20 & Alt6 & 8.6 \\
8 & GW & 8.6 & 21 & RW + 0.3 LF & 8.6 \\
9 & B (1:1) & 0 & 22 & RW + 0.4 LF & 8.6 \\
10 & B (1:1) & 1.72 & 23 & RW + 0.5 LF & 8.6 \\
11 & B (1:1) & 4.3 & 24 & B + 0.3 LF & 8.6 \\
12 & B (1:1) & 8.6 & 25 & B + 0.4 LF & 8.6 \\
13 & Alt1 & 0 & 26 & B + 0.5 LF & 8.6 \\
\hline
\end{tabular}

* RW = recycled water, ${ }^{\#} \mathrm{GW}=$ good-quality water, ${ }^{+} \mathrm{B}(1: 1)=$ blending of RW and GW in a 1:1 ratio, "Alt1 = monthly alternate use of RW and GW, ${ }^{+}$Alt6 = six-monthly alternate use of RW and GW, and Cal = calcareous soil.

Table 2. Different water quality and gypsum application scenarios performed for the hard red-brown (HRB) soils under almonds.

\begin{tabular}{cccccc}
\hline Scenario No. & $\begin{array}{c}\text { Water } \\
\text { Quality }\end{array}$ & $\begin{array}{c}\text { Gypsum } \\
\text { Application } \\
\text { (t/ha) }\end{array}$ & Scenario No. & $\begin{array}{c}\text { Water } \\
\text { Quality }\end{array}$ & $\begin{array}{c}\text { Gypsum } \\
\text { Application } \\
\text { (t/ha) }\end{array}$ \\
\hline 1 & RW & 0 & 17 & Alt1 & 1.72 \\
2 & RW & 1.72 & 18 & Alt1 & 4.3 \\
3 & RW & 4.3 & 19 & Alt1 & 8.6 \\
4 & RW & 8.6 & 20 & Alt1 & 12.9 \\
5 & RW & 12.9 & 21 & Alt6 ${ }^{+}$ & 0 \\
6 & GW & 0 & 22 & Alt6 & 1.72 \\
7 & GW & 1.72 & 23 & Alt6 & 4.3 \\
8 & GW & 4.3 & 24 & Alt6 & 8.6 \\
9 & GW & 8.6 & 25 & Alt6 & 12.9 \\
10 & GW & 12.9 & 26 & RW + 0.3 LF & 8.6 \\
11 & B (1:1) & 0 & 27 & RW + 0.4 LF & 8.6 \\
12 & B (1:1) & 1.72 & 28 & RW + 0.5 LF & 8.6 \\
13 & B (1:1) & 4.3 & 29 & B + 0.3 LF & 8.6 \\
14 & B (1:1) & 8.6 & 30 & B + 0.4 LF & 8.6 \\
15 & B (1:1) & 12.9 & 31 & B + 0.5 LF & 8.6 \\
16 & Alt1 & 0 & & & \\
\hline
\end{tabular}

* RW = recycled water, ${ }^{\#} \mathrm{GW}=$ good-quality water, ${ }^{+} \mathrm{B}(1: 1)=$ blending of RW and GW in a 1:1 ratio, "Alt1 = monthly alternate use of RW and GW, ${ }^{+}$Alt $6=$ six-monthly alternate use of RW and GW, HRB = hard red-brown, $\mathrm{LF}=$ leaching fraction.

Apart from the scenarios listed in Table 1, five more scenarios involving a much higher annual gypsum application (12.9 t/ha) were performed for hard red-brown (HRB) soils. Three leaching scenarios were carried out to evaluate the impact of different leaching fractions (LF; 0.3, 0.4, 0.5) for recycled water and blending irrigation options.

Gypsum applications are usually estimated based on soil texture, cation exchange capacity, ESP of the soil, soil depth, crop type, water quality, etc. [55-57]. The estimated 
amount of gypsum is mixed in the surface soil layer, usually in the $0-20 \mathrm{~cm}$ depth. However, the effectiveness of gypsum depends on many factors, such as the purity of gypsum, its granule size, application method, mixing uniformity, etc. [33]. In addition to a control scenario (zero gypsum application), we have considered three typical gypsum application rates $(1.72,4.3$, and $8.6 \mathrm{t} / \mathrm{ha})$, which fall within the general recommended range of gypsum applications based on the sodicity (ESP) classes occurring in Australian soils [58]. These classes are slightly sodic $(\mathrm{ESP}<6)$, sodic $(\mathrm{ESP}=6-15)$, and highly sodic $(\mathrm{ESP}>15)$ for alkaline soils [59]. However, farmers sometimes resort to much higher amounts of gypsum. Therefore, we have also tested a higher dose of $12.9 \mathrm{t} / \mathrm{ha}$ as an annual application, especially in hard red-brown soils (Table 2), where inherent subsoil constraints, including high sodicity, are a common occurrence.

\subsection{Model Description}

A detailed description of the HYDRUS-1D model is available in Šimůnek et al. [53,60]. The one-dimensional Richards equation, which assumes that the air phase plays an insignificant role in liquid flow processes and that water flow due to thermal gradients can be neglected, is solved in HYDRUS-1D using a Galerkin-type linear finite element scheme [51]. The governing one-dimensional water flow equation is described as:

$$
\frac{\partial \theta}{\partial t}=\frac{\partial}{\partial z}\left[K(h)\left(\frac{\partial h}{\partial z}+\cos \alpha\right)\right]-S(h, z, t)
$$

where $\theta$ is the soil water content $\left(\mathrm{L}^{3} \mathrm{~L}^{-3}\right), t$ is the time $(\mathrm{T}) ; h$ is the soil water pressure head $(\mathrm{L}), z$ is the vertical coordinate (positive upwards), $K(h)$ is the hydraulic conductivity function $\left(\mathrm{LT}^{-1}\right), \alpha$ is the angle between the flow direction and the vertical axis (e.g., 1 for vertical flow and 0 for horizontal flow), and $S(h, z, t)$ is a sink term accounting for water uptake by plant roots $\left(\mathrm{L}^{3} \mathrm{~L}^{-3} \mathrm{~T}^{-1}\right)$.

The HYDRUS-1D model is run with the best available soil, crop, climate, and irrigation management parameters. The soil parameters were mostly directly measured on representative soil samples or estimated using auxiliary soil data. Most of the crop parameters are from the literature, although some calibrated parameters were available for wine grapes. Climate data were partly measured on-site (historical climate) and partly derived from downscaled climate projections. Irrigation management parameters were obtained from surveys of irrigators [48]. The model was, thus, not specifically calibrated, as preference was given to the use of the measured input parameters. Note that estimating model parameters through calibration using an inadequate conceptual model could lead to the so-called parameter bias [61].

\subsection{Model Input Parameters}

\subsubsection{Soil Hydraulic Characteristics}

The soil hydraulic characteristics are modelled using the water retention and hydraulic conductivity functions described by the van Genuchten-Mualem constitutive relationships [62]:

$$
\begin{gathered}
\theta(h)=\theta_{r}+\frac{\theta_{s}-\theta_{r}}{\left[1+(\alpha h)^{h}\right]^{m}} h<0 \\
\theta(h)=\theta_{s} h \geq 0 \\
K(h)=K_{s} S_{e}^{I}\left[1-\left(1-S e^{1 / m}\right)^{m}\right]^{2}
\end{gathered}
$$

where $\theta_{s}$ is the saturated water content $\left(\mathrm{L}^{3} \mathrm{~L}^{-3}\right), \theta_{r}$ is the residual water content $\left(\mathrm{L}^{3} \mathrm{~L}^{-3}\right)$, $K_{s}$ is the saturated hydraulic conductivity $\left(\mathrm{LT}^{-1}\right), l$ is a shape factor, and $m, \alpha$, and $n$ are empirical shape parameters, where $m=1-1 / n . S_{e}$ is the relative saturation (dimensionless), which is defined as

$$
S_{e}=\frac{\theta-\theta_{r}}{\theta_{s}-\theta_{r}}
$$


The parameters $\left(\theta_{r}, \theta_{s}, K_{S}, \alpha\right.$, and $\left.n\right)$ for different soils were derived from the measurements on soil cores collected from soil profiles from the NAP, as described in Section 2.1. Average parameter values were then derived for the two most important textural soil groups (Appendix A, Table A1).

\subsubsection{Solute Transport Properties for UNSATCHEM}

The major ion chemistry module UNSATCHEM enables the simulation of equilibrium geochemical reactions involving $\mathrm{Ca}, \mathrm{Mg}, \mathrm{Na}, \mathrm{K}, \mathrm{SO}_{4}, \mathrm{Cl}, \mathrm{NO}_{3}, \mathrm{H}_{4} \mathrm{SiO}_{4}, \mathrm{HCO}_{3}$, and $\mathrm{CO}_{2}[60,63]$. The model accounts for equilibrium chemical reactions between these components, such as aqueous complexation, cation exchange, and precipitation-dissolution. For precipitation-dissolution of calcite and dissolution of dolomite, either equilibrium or multicomponent kinetic expressions are used, which include both forward and back reactions. Other precipitation-dissolution reactions considered involve gypsum $\left(\mathrm{CaSO}_{4} \cdot 2 \mathrm{H}_{2} \mathrm{O}\right)$, hydromagnesite $\left(\mathrm{Mg}_{5}\left(\mathrm{CO}_{3}\right) 4(\mathrm{OH})_{2} \cdot 4 \mathrm{H}_{2} \mathrm{O}\right)$, nesquehonite $\left(\mathrm{MgCO}_{3} \cdot 3 \mathrm{H}_{2} \mathrm{O}\right)$, and sepiolite $\left(\mathrm{Mg}_{2} \mathrm{Si}_{3} \mathrm{O}_{7} \cdot 5(\mathrm{OH}) \cdot 3 \mathrm{H}_{2} \mathrm{O}\right)$. Since the ionic strength of soil solutions can vary considerably with time and space and often reach high values, both modified Debye-Hückel and Pitzer expressions are incorporated into the model as options to calculate single-ion activities.

Initial average concentrations of soil solution species, soil exchange cations, and estimated Gapon selectivity coefficients for soils collected from the NAP area are given in $[9,10]$. Note that the initial soil solution is brought into equilibrium with the cation exchange complex during the model warming up period (1970-2018).

\subsubsection{Root Water Uptake Parameters}

Water extraction $S\left(h, h_{s}, x, z, t\right)$ from the soil is computed according to the Feddes macroscopic approach [64]. In this method, the potential transpiration rate, $T_{p}$, is distributed over the root zone using a normalized root-density distribution function $\{\beta(x, z, t)\}$ and multiplied by dimensionless water $\alpha_{1}(h)$ and salinity $\alpha_{1}\left(h_{s}\right)$ stress response functions as:

$$
S\left(h, h_{s}, x, z, t\right)=\alpha_{1}\left(h, h_{s}, x, z, t\right) S_{p}(x, z, t)=\alpha_{1}\left(h, h_{s}, x, z, t\right) \beta(x, z, t) T_{p}(t)
$$

This model reduces potential plant root water uptake rates according to the local soil water pressure head, $h$, and osmotic head, $h_{s}$, at any point in the root zone. This model defines how potential transpiration $\left(T_{p}\right)$ is reduced when the soil is no longer capable of supplying the amount of water required by plants under prevailing climatic and soil conditions. The multiplicative model for the uptake reduction due to the osmotic stress is considered in this study:

$$
\alpha_{1}\left(h, h_{s}\right)=\alpha_{1}(h) \alpha_{1}\left(h_{s}\right)
$$

The reduction of root water uptake due to the water stress, $\alpha_{1}(h)$, is described as:

$$
\alpha_{1}(h)=\left\{\begin{array}{cc}
0, & h>h_{1} \text { or } h \leq h_{4} \\
\frac{h-h_{1}}{h_{2}-h_{1}}, & h_{2}<h \leq h_{1} \\
1, & h_{3}<h \leq h_{2} \\
\frac{h-h_{4}}{h_{3}-h_{4}}, & h_{4}<h \leq h_{3}
\end{array}\right.
$$

where $h_{1}, h_{2}, h_{3}$, and $h_{4}$ are the threshold model parameters. Water uptake is at the potential rate when the pressure head is between $h_{2}$ and $h_{3}$, decreases linearly when $h>h_{2}$ or $h<h_{3}$, and becomes zero when $h<h_{4}$ or $h>h_{1}$. These critical values of the pressure head for viticulture and almonds were taken from previous investigations in South Australia [65-67].

The threshold model uses two variables to simulate the osmotic stress $\alpha_{1}\left(h_{s}\right)$ : the osmotic head, below which water is extracted at the maximum rate, and the slope, i.e., a fractional reduction of water uptake per unit increase in the osmotic head above the threshold. These parameters were obtained from Zhang et al. [68] for wine grapes and from Ayers and Westcott [69] for almonds. 


\subsubsection{Estimation of Potential Evaporation $\left(E_{s}\right)$ and Potential Transpiration $\left(T_{p}\right)$}

The HYDRUS-1D/UNSATCHEM [44] model requires daily inputs of rainfall as well as potential evaporation $\left(E_{s}\right)$ and potential transpiration $\left(T_{p}\right)$. Therefore, the daily $E_{s}$ and $T_{p}$ values for all wine grapes and almonds for current and future climates were estimated following the FAO-56 dual crop coefficient (DCC) approach [70]. The FAO-56 DCC methodology requires a considerable amount of data for crops, soils, and climate. All relevant information and required data for this approach for the NAP soils and crops are given in Mallants et al. [10] and Phogat et al. [12]. Daily climate data for the historical climate (1970-2018) were obtained from the Bureau of Meteorology (BOM), the Edinburgh RAAF station, while future climate (2018-2050) data were taken from the Goyder climate change median climate projections for the same station [71].

The median data are based on the downscaled series obtained from the GFDLESM2M Global Climate Model (GCM), one of the six better-performing GCMs. A median decrease in annual rainfall by 2050 is $6.8 \%$ (relative to the 1986-2005 baseline), the 10th percentile decrease is $8.8 \%$, and the 95 th percentile decrease is $3.5 \%$ (for the intermediateemission Representative Concentration Pathway RCP 4.5). RCP 4.5 is a scenario representing long-term global emissions of greenhouse gases, short-lived species, and land-use-cover, which stabilizes radiative forcing at $4.5 \mathrm{~W} / \mathrm{m}^{2}$ (approximately $650 \mathrm{ppm} \mathrm{CO}_{2}$-equivalent) in the year 2100 without ever exceeding that value [72]. A single future climate scenario is used rather than a range of future climate scenarios to keep the overall number of modelling scenarios manageable.

Apart from daily $E_{s}$ and $T_{p}$, the irrigation requirements for wine grape and almonds were also estimated following the FAO-56 dual crop coefficient (DCC) approach [70], as discussed in detail by Mallants et al. [10] and Phogat et al. [12,73]. For wine grapes, measured LAI values were taken from similar studies $[67,74]$ in the study area. In addition, values for canopy geometry and fractional cover for wine grape previously calibrated by Phogat et al. [65] have been used here. The functional relation followed in the FAO dual crop coefficient approach [70] is given as:

$$
E T_{C}=\left(K_{c b}+K_{e}\right) E T
$$

where $E T_{C}$ is crop evapotranspiration $\left(\mathrm{LT}^{-1}\right), E T_{0}$ is reference crop evapotranspiration $\left(\mathrm{LT}^{-1}\right), K_{c b}$ is the basal crop coefficient, representing the plant transpiration component, and $K_{e}$ is the soil evaporation coefficient. Some of the basic information, such as $K c b$, crop duration, plant height, rooting depth, and depletion factor, is available from FAO-56 [70]. The details on data requirements and other relevant information for each crop, soil, and climate conditions can be found in Mallants et al. [10]. In this approach, standard $K_{c b}$ values [70] of the crops were adjusted for the local climate, taking into consideration crop height, wind speed, and minimum relative humidity averages. Estimated $K_{c b}$ 's in the current study compare well with previously calibrated values for wine grape [58]. Soil-specific information (soil texture, field capacity, $\theta f c$; permanent wilting point, $\theta w p$; readily available water, $R A W$; and total available water, $T A W$ ) has been drawn from the soil analyses [50].

The values of daily potential transpiration $\left(T_{p}\right)$ and soil evaporation $\left(E_{s}\right)$ were used as time-variable boundary conditions in the HYDRUS model, along with the irrigation schedule for different crops and precipitation received at the site during the simulation period. The amount and timing of irrigation were also imposed as a time-variable flux boundary.

\subsection{Modelling Domain, Initial and Boundary Conditions}

Simulations for vine grapes and almonds were performed for a $200 \mathrm{~cm}$ deep soil profile divided into 100 finite elements. The finite element nodes were distributed so that elements at the soil surface were half the size of the elements at the bottom of the soil profile to ensure fine discretization at the soil surface where major water and solute dynamic processes occur. The measured textural heterogeneity in the Cal and HRB soils 
in the NAP area was maintained by dividing the domain into five soil layers $(0-15,15-30$, $30-60,60-100$, and 100-200 cm). At the soil surface, an atmospheric boundary condition with surface runoff was imposed. A free drainage boundary condition was applied at the bottom boundary. For solute transport, a concentration flux boundary condition was used at the soil surface, and a zero-concentration gradient boundary condition was imposed at the bottom to allow gravitational outflow with drainage water. A constant pressure head of $-100 \mathrm{~cm}$ was considered to initialize the model runs. The measured daily rainfall and calculated daily $E_{s}$ and $E_{p}$ for different crops were applied during the warmup period (1970-2018). The measured soil solution and exchange parameters were assumed as initial conditions for the multicomponent solute transport module.

Initially, the model was warmed up for 48 years from July 1970 to June 2018 using the historical climate parameters from the Bureau of Meteorology (BOM) Station No. 023,083 at the Edinburgh RAAF (latitude-34.7111, longitude 138.6222, elevation $17 \mathrm{~m}$ ) to initialize the soil water contents and to attain equilibrium conditions for chemical species for both soils, crops, and irrigation quality and management scenarios. Subsequently, the model was run using the future climate (2018-2050) projection data for the same station [71]. Soil amelioration doses (Go, G1, G2, G3, and G4) and leaching fractions (LF0.3, LF0.4, and LF0.5) were introduced during the future climate simulations.

More details about the input parameters required for executing various management scenarios using HYDRUS-1D (UNSATCHEM) have been described in our previous publications $[11,12]$ and project reports $[10,48,50]$. However, it is worth mentioning that we have tested a new subroutine implemented in HYDRUS-1D/UNSATCHEM specifically for this study, i.e., yearly applications of gypsum to manage adverse impacts of RW on the soil properties, especially soils' SAR and ESP. Therefore, simulations were conducted with different annual applications of gypsum to optimize the application dose for different NAP soils for sustainable horticultural production.

\subsection{Model Calibration}

This study was focused on assessing the feasibility of the expansion of irrigated agriculture in the Northern Adelaide Plain, South Australia, by utilizing the increased capacity of recycled water (RW) from the water treatment plant. The RW water delivery and the irrigation system in the primary production area selected for the irrigation expansion are not yet operational. Therefore, conducting a field experiment with RW on various soil groups (or even a single soil group) was not possible. HYDRUS-2D (the two-dimensional version of HYDRUS) has been sufficiently calibrated and validated in the adjoining area (Riverland) for water balance and salinity dynamics under a range of horticultural industries, including almonds, grapevine, and citrus [65-67]. These studies provide convincing evidence that the HYDRUS model can generate reliable estimates when field-measured input data are used for simulations. Similarly, HYDRUS-UNSATCHEM has been successfully calibrated and validated in other studies involving a variety of water qualities, crops, and environmental conditions (e.g., [75-78]). Numerous other published studies [79-82] involving UNSATCHEM simulations similar to the current study have been able to unravel varied intricacies of the soil-plant-atmosphere system and generate valuable information. Therefore, we strongly believe that in spite of the lack of site-specific model calibration, numerical simulations with measured and reliable input data can produce reliable outcomes.

\section{Results and Discussion}

Different soils responded to recycled water irrigation differently, depending on the dynamic interactions between soil solution and exchange properties of the soil. Therefore, management options are discussed below for different soil types. 


\subsection{Management Options in the Calcareous Soil}

\subsubsection{Changes in Soil $\mathrm{pH}$ in the Calcareous Soil}

In the calcareous soil, average $\mathrm{pH}$ values in the $0-15 \mathrm{~cm}$ soil depth ranged from 7.3 to 8.2 under different irrigation quality scenarios (RW, GW, B, Alt1, and Alt6) with no gypsum additions (Figure 1). The $\mathrm{pH}$ values decreased with depth except under good-quality (GW) irrigation. Modelled values are comparable to those estimated with the $0.01 \mathrm{M}$ $\mathrm{CaCl}_{2}$ solution in the calcareous soil profiles collected from the study area [50]. It is worth noting that the $\mathrm{pH}$ values stabilized for the scenarios with $8.6 \mathrm{t} / \mathrm{ha}$ annual gypsum (G3) applications. The overall average reduction in $\mathrm{pH}$ in various depths, irrespective of water quality and gypsum doses, ranged from 4 to $6.2 \%$. Simulated average $\mathrm{pH}$ values were 7.6, 7.5 , and 7.3 in the $0-15,30-60$, and $90-120 \mathrm{~cm}$ soil depths, respectively.
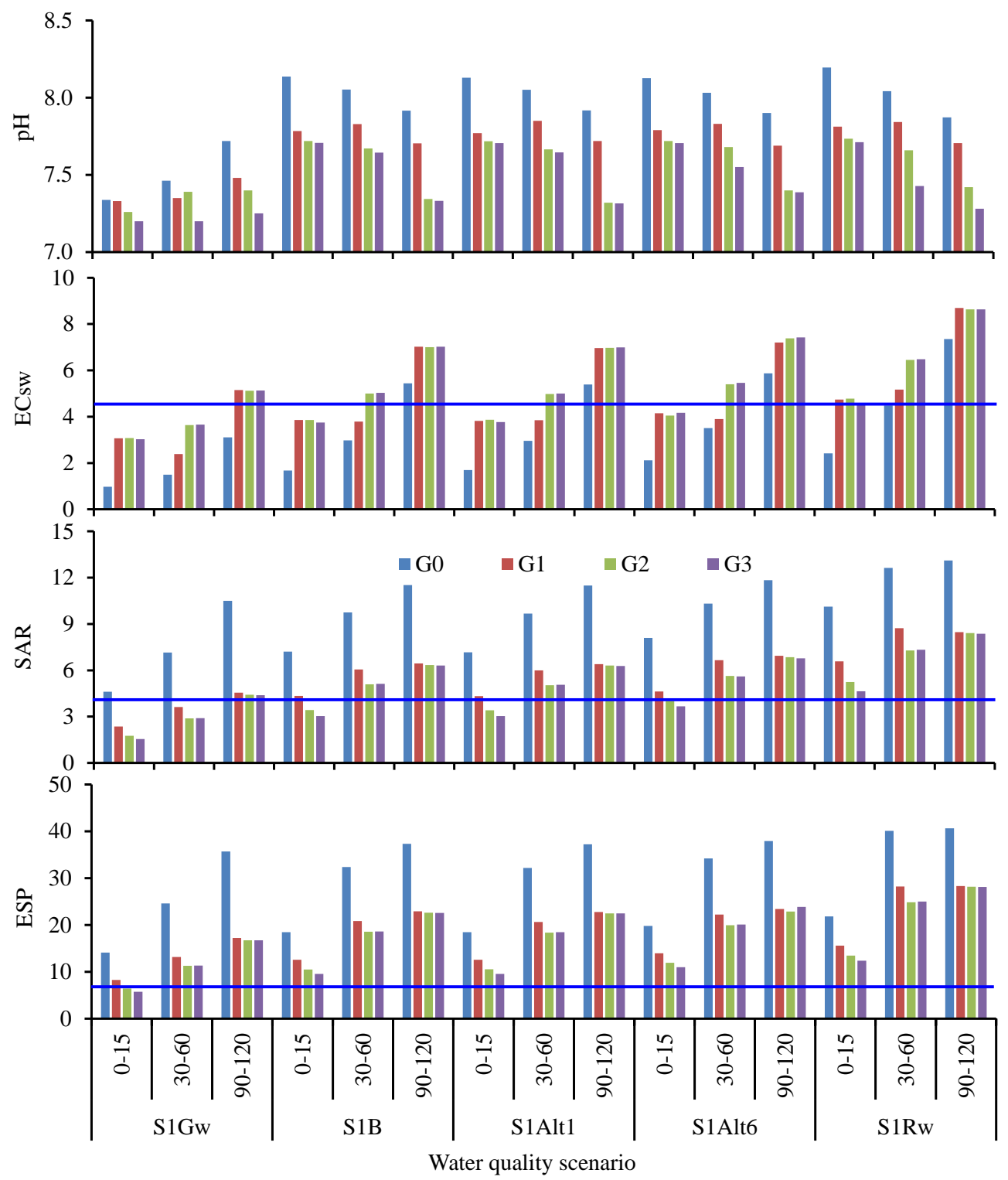

Figure 1. Average values of $\mathrm{pH}, \mathrm{EC}_{\mathrm{Sw}}, \mathrm{SAR}$, and $\mathrm{ESP}$ in the calcareous soil (S1) under long-term (2018-2050) irrigation of wine grapes with different water qualities (recycled water, RW; good water, GW; blending RW and GW in a 1:1 ratio, B; RW and GW used in monthly cycles, Alt1; RW and GW used in half-yearly cycles, Alt6) and annual gypsum additions of 0 (G0), 1.7 (G1), 4.3 (G2), and 8.6 (G3) t/ha. 


\subsubsection{Salinity Distribution in the Calcareous Soil}

Average $\mathrm{EC}_{\mathrm{sw}}$ in the $0-15,30-60$, and $90-120 \mathrm{~cm}$ soil depths in the G0 scenario were lower than the salinity threshold of wine grapes (i.e., $4.2 \mathrm{dS} / \mathrm{m}$; [68]), except for the RW, blending, and cyclic water use treatments in the 90-120 cm depth (Figure 1). However, the addition of gypsum increased $\mathrm{EC}_{\mathrm{sw}}$ in all depths for all water quality scenarios. Average annual $\mathrm{EC}_{\mathrm{sw}}$ for scenarios with annual gypsum additions of 1.7, 4.3, and 8.6 $\mathrm{t} / \mathrm{ha}$ increased by $43,55.8$, and $55.6 \%$, respectively (Figure 1 ). Gypsum is a moderately soluble salt, which can increase soluble salts in the soil. As a soil amendment, it improves the cation composition on the soil exchanger by replacing $\mathrm{Na}$ ions with $\mathrm{Ca}$ ions, which reduces the ESP of the soil. Overall, there was a general pattern of increasing salt storage with depth in the calcareous soil, irrespective of irrigation water quality. However, the extent of salinity build-up depends on the ionic composition of the irrigation water.

Similarly, annual $\mathrm{EC}_{\mathrm{sw}}$ values were also below the salinity threshold of sensitive crops $\left(4 \mathrm{dS} / \mathrm{m}=\mathrm{EC}_{\mathrm{e}}\right.$ of $\left.2 \mathrm{dS} / \mathrm{m}\right)$, such as vegetables and wine grapes in the $0-15 \mathrm{~cm}$ soil depth under all types of irrigation, including with recycled water (RW), blending (B), and cyclic use (Alt1 and Alt6) with an 8.6 t/ha gypsum application (Figure 2). Stevens et al. [83] estimated the $\mathrm{EC}_{\mathrm{e}}$ values to be $2.8 \mathrm{dS} / \mathrm{m}$ (or an equivalent $\mathrm{EC}_{\mathrm{sw}}$ of $5.6 \mathrm{dS} / \mathrm{m}$ ) in the $20 \mathrm{~cm}$ depth of the NAP soil irrigated with recycled water for 10-28 years. However, their virgin soils had $\mathrm{EC}_{\mathrm{e}}$ values comparable with $\mathrm{EC}_{\mathrm{e}}$ values in scenarios irrigated with good-quality water. On the other hand, $\mathrm{EC}_{\mathrm{sw}}$ in the 30-60 $\mathrm{cm}$ depth showed an increasing trend for all irrigation water qualities, with average annual values ranging from 1.5 to $4.49 \mathrm{dS} / \mathrm{m}$ in different scenarios. An increase of $53-86 \%$ was comparable to an increase in the $0-15 \mathrm{~cm}$ depth (Figure 1). $\mathrm{EC}_{\mathrm{sw}}$ in the RW scenario compares closely with the Stevens et al. [25] values in the $20 \mathrm{~cm}$ depth. Similarly, in the $90-120 \mathrm{~cm}$ depth, average $\mathrm{EC}_{\mathrm{sw}}$ varied from 3.11 to $7.35 \mathrm{dS} / \mathrm{m}$, a fourfold increase compared to the values in the $0-15 \mathrm{~cm}$ soil depth (Figure 1). These values are lower than the salinity tolerance threshold for moderately tolerant and tolerant crops [48]. In contrast, Stevens et al. [83] observed much higher salinities in deeper depths in virgin soils $\left(E C_{\mathrm{e}}=6.9 \mathrm{dS} / \mathrm{m}\right.$ or approximately equivalent $\left.\mathrm{EC}_{\mathrm{sw}}=13.8 \mathrm{dS} / \mathrm{m}\right)$ in the NAP region. It was also observed that when wastewater was used to irrigate grapevines, inferior growth was associated with inadequate accumulation of nutrients in vine biomass [84]. Additionally, a progressive increase in soil salinity throughout several years of irrigation was observed $[85,86]$. However, a reduction in hydraulic conductivity, textural differences, and inherent subsoil constraints (e.g., sodicity) in deeper depths may also play a vital role in the salt accumulation in these soils. Apparently, the occurrence of such soil characteristics may reduce the salts' leaching, thus favoring storage in deeper depths in the calcareous soil.

\subsubsection{Dynamics of the Sodium Adsorption Ratio (SAR) in the Calcareous Soil}

Annual gypsum additions at a rate of 1.7, 4.3, and $8.6 \mathrm{t} /$ ha showed a remarkable reduction in average SAR values (Figure 1). Initial average SAR values (4.6-13.1) decreased by almost $50 \%$ with annual applications of $1.7 \mathrm{t} /$ ha of gypsum (G1). These values were further reduced by $1-25 \%$ with increased annual gypsum additions of $4.3(\mathrm{G} 2)$ and $8.6 \mathrm{t} / \mathrm{ha}$ (G3). However, this impact was observed only in the surface soil layer $(0-15 \mathrm{~cm})$. The resulting SAR values fell below the critical threshold $(S A R<4)$ for calcareous soils [12] under irrigation with all water qualities, except in the case of continuous use of recycled water. For example, in the RW scenario, SAR (10-13) values decreased to 4.6-8.4 with the annual gypsum application of $8.6 \mathrm{t} / \mathrm{ha}$. An almost similar reduction in SAR was observed for other water quality scenarios. 


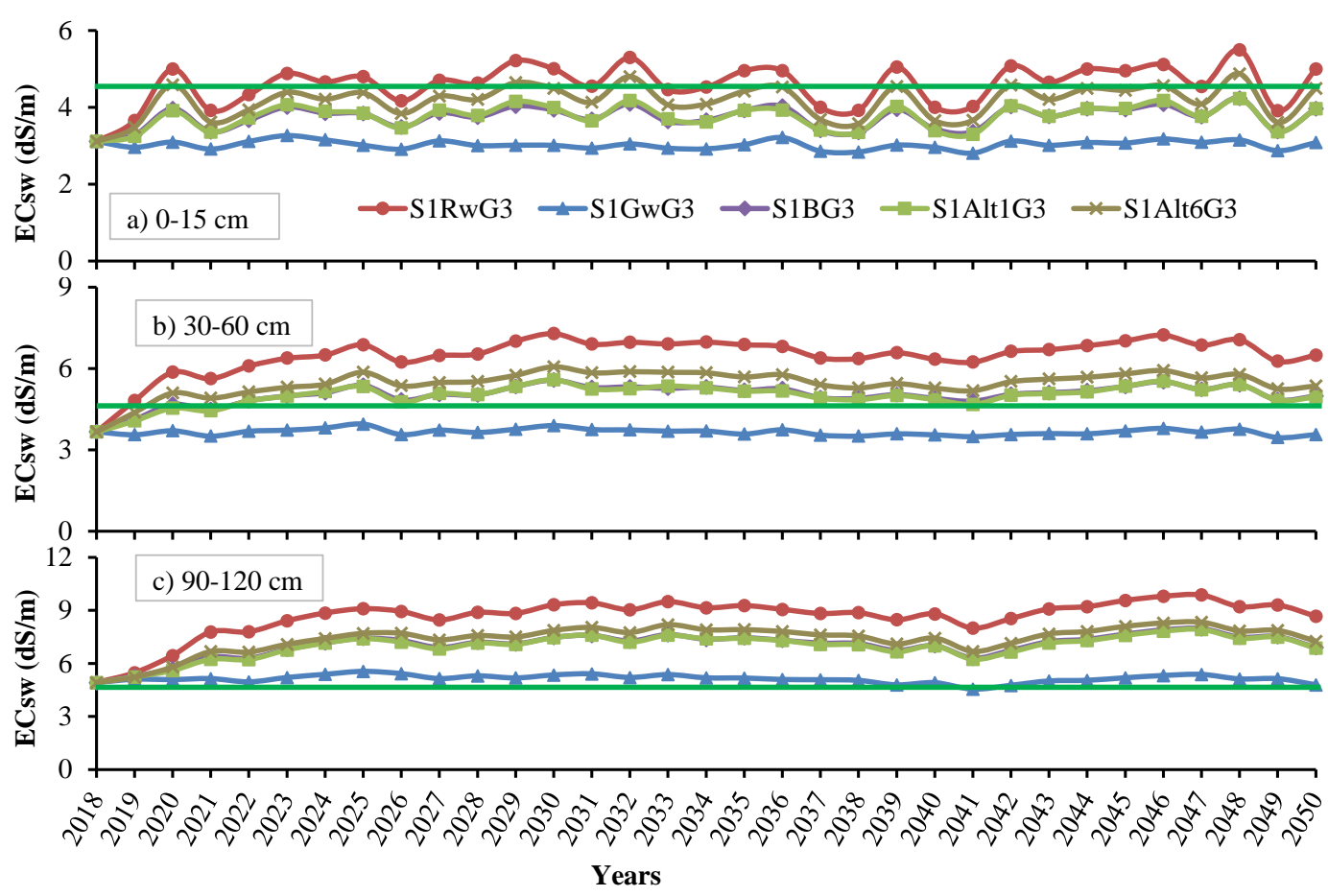

Figure 2. Impact of different water qualities (recycled water, RW; good water, GW; blending of RW and GW in a 1:1 ratio, B; RW and GW used in monthly cycles, Alt1; and RW and GW used in half-yearly cycles, Alt6) and annual gypsum applications of $8.6 \mathrm{t} / \mathrm{ha}(\mathrm{G} 3)$ on $\mathrm{EC}_{\mathrm{sw}}$ for calcareous soil (S1) under wine grape cultivation.

Average annual SARs in different depths obtained with the annual gypsum application of $8.6 \mathrm{t} / \mathrm{ha}$ are shown in Figure 3. SAR in the surface soil layer $(0-15 \mathrm{~cm})$ was effectively maintained below the calcareous soil threshold $(\mathrm{SAR}=4)$ under all irrigation treatments, except for RW during some years, although these values were close to the critical threshold as well. In the $30-60 \mathrm{~cm}$ soil depth, average annual SAR values decreased significantly compared to G0, but remained above the critical value in all water quality scenarios except for GW. Average annual SAR remained constant during the initial 2-3 years, then increased before stabilizing after 10-12 years of irrigation at values larger than 6 for RW and between 4 and 6 for blending and a cyclic use of RW and GW. Similarly, in the 90-120 cm depth, SAR was maintained near the critical value for 5-6 years of irrigation, then increased and attained a constant value after 20 years of irrigation. Subsequent small changes in the SAR at different soil depths were induced by the rainfall variability rather than the water quality as the soil profile attains a quasi-steady state. The final value was higher than 10 for RW and between 7 and 9 for blending and cyclic treatments. A gradual increase in SAR in deeper depths of the calcareous soil seems to be influenced by RW irrigation. Therefore, annual gypsum applications of $8.6 \mathrm{t} / \mathrm{ha}$ effectively reduced SAR below the threshold in the surface soil $(0-15 \mathrm{~cm})$ but could not fully reclaim the soil in deeper depths.

Average annual SAR values for RW irrigation were higher than the threshold (SAR =4) for calcareous soils estimated in the previous $[10,12]$ and current studies. However, it is appropriate to note that reclaimed SAR values are below the US Salinity Lab classification [87]. It is expected that marginally higher SAR values may not dramatically impact the overall crop performance, even though they may lead to high ESP in the soils, which is visible in average ESP values (Figure 1). Apart from RW, blending (B) and cyclic (Alt1 and Alt6) irrigation scenarios also showed ESP values corresponding to the sodic class (ESP 6-15\%), as per the Australian sodic soil categorization [58]. However, these values are well below the US standards (ESP > 15\%; [87]) defining sodic soils. 


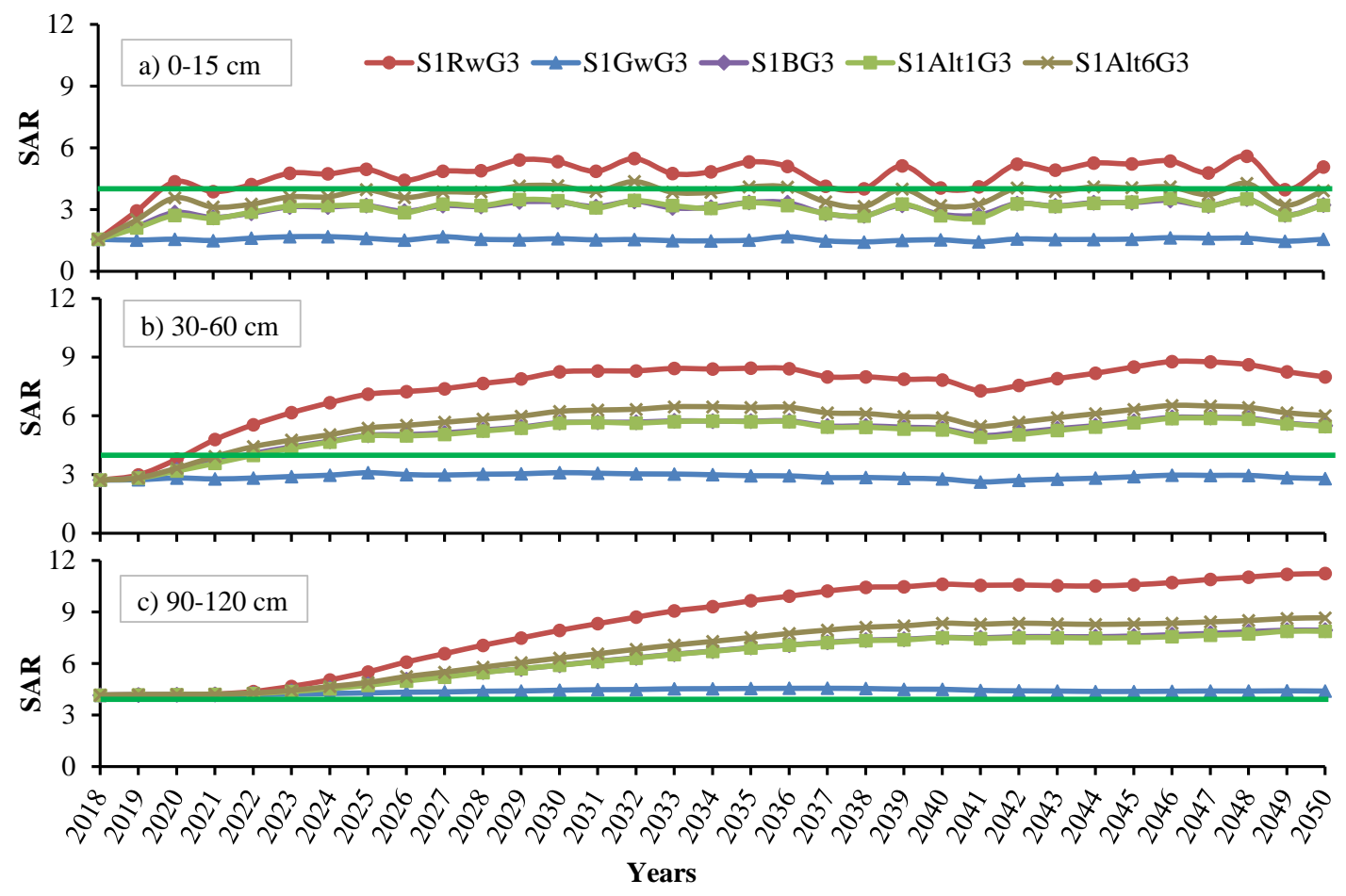

Figure 3. Impact of different water qualities (recycled water, RW; good water, GW; blending RW and GW in a 1:1 ratio, B; RW and GW used in monthly cycles, Alt1; and RW and GW used in half-yearly cycles, Alt6) and annual gypsum applications of $8.6 \mathrm{t} / \mathrm{ha}$ (G3) on annual SAR for calcareous soil (S1) under wine grape cultivation.

\subsubsection{Exchangeable Sodium Percentage (ESP) in the Calcareous Soil}

Average annual ESP for different treatments without gypsum ranged from 14.1$21.9,24.6-40$, and $35.7-40.6 \%$ in the $0-15,30-60$, and $90-120 \mathrm{~cm}$ soil depths, respectively (Figure 1). However, annual gypsum applications of $1.7 \mathrm{t} /$ ha reduced ESP to between one-third and one-half of the corresponding values without gypsum applications (Figure 1). Further additions of gypsum at 4.3 and $8.6 \mathrm{t} /$ ha reduced ESP further, but the impact was much smaller and only observed in the surface depth $(0-15 \mathrm{~cm})$. Average ESP values in the 30-60 and 90-120 cm depths under different water use scenarios remained higher than the threshold, with most values falling into the highly sodic class (ESP > 15; [58]), which is equivalent to the normal threshold in the US standards (ESP > 15\%; [87]) defining sodic soils. In fact, irrigation with good-quality water also showed ESP values above the threshold (ESP $>6 \%$ ) in the $90-120 \mathrm{~cm}$ depth. The combination of other water qualities and gypsum applications had only a small impact on reducing SAR and ESP in the soils in deeper depths. Application and mixing of gypsum in the upper soil layer $(0-20 \mathrm{~cm}) \mathrm{had}$ a less positive impact in deeper depths.

The impact of gypsum applications of $8.6 \mathrm{t} / \mathrm{ha}$ on annual ESP values in different depths is less prominent as the ESP values remained higher than the threshold (Figure 4). It is interesting to note that ESP values under GW irrigation remained almost constant over the entire simulation period (2018-2050). ESP values lower than critical values were observed only in the surface depths. Annual ESP in the 30-60 and 90-120 cm depths showed a similar trend as observed for SAR. Especially in deeper depths, ESP remained constant for 6-7 years, then gradually increased and stabilized at a value larger than 27 and 33 under the RW treatment after $10(30-60 \mathrm{~cm})$ and 20 years $(90-120 \mathrm{~cm})$ years of irrigation, respectively (Figure 4). Subsequent small changes in the ESP were associated with the rainfall variability. This further suggests that observed constant ESP values probably represent inherent sodicity that typically occurs in the NAP soils in deeper depths and is more prevalent in calcareous soils. Assouline and Narkis [24] also found that high SAR and high salinity of treated effluent irrigation water are often accompanied by high ESP 
values that increase with depth. Nonetheless, high sodicity in the $90-120 \mathrm{~cm}$ soil depth may not impact plant growth, including wine grapes, as more than $90 \%$ of the roots of agricultural crops remain within the first-meter soil depth [70]. Likewise, $50 \%$ of the roots of cereals, pulses, and oilseed crops are accumulated within the 8-20 cm soil depth [88]. Nevertheless, such high ESP conditions can lead to restricted drainage or perched water table conditions, usually prevalent in the NAP region. Many studies have shown that ESP generally increases linearly with SAR of irrigation water [89-91].

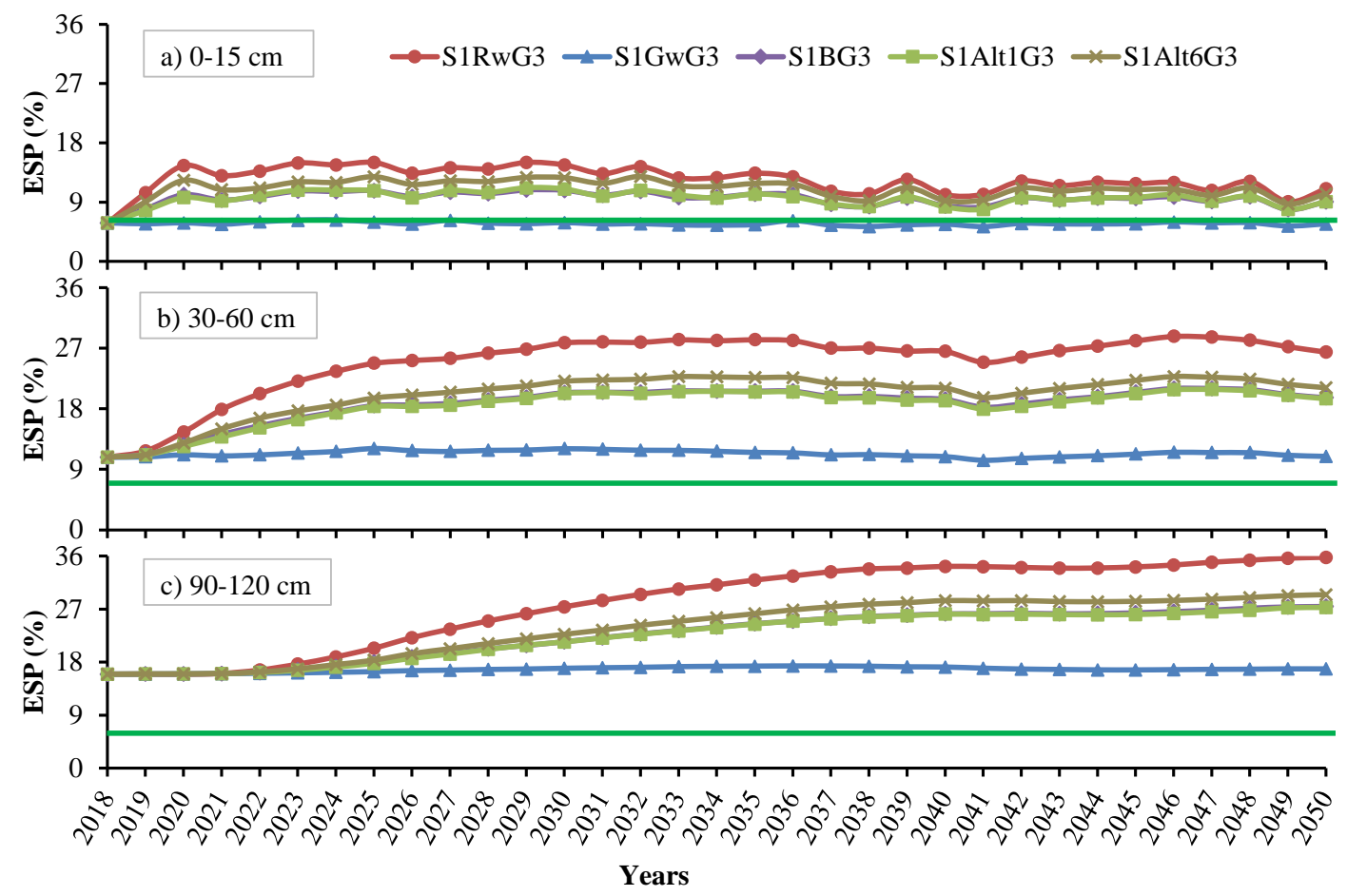

Figure 4. Impact of different water qualities (recycled water, RW; good water, GW; blending RW and GW in a 1:1 ratio, B; RW and GW used in monthly cycles, Alt1; and RW and GW used in half-yearly cycles, Alt6) and annual gypsum applications of $8.6 \mathrm{t} / \mathrm{ha}$ (G3) on annual ESP for calcareous soil (S1) under wine grape cultivation.

\subsubsection{Role of Leaching on Salinity Control}

It is evident from the discussion in the previous section that annual gypsum applications at a rate of $8.6 \mathrm{t} / \mathrm{ha}$ and blending or cyclic use irrigation options are unable to lower $\mathrm{EC}_{\mathrm{sw}}, \mathrm{SAR}$, and ESP of calcareous soils as per Australian standards, especially in deeper depths. Therefore, simulations were conducted to evaluate the impact of different leaching fractions $(0.2,0.3,0.4$, and 0.5$)$ on reducing the harmful impact of RW irrigation. It can be seen that increasing the leaching fraction (LF) from 0.2 to 0.5 has a moderate effect on reclamation of the $0-15 \mathrm{~cm}$ soil depth because $\mathrm{EC}_{\mathrm{sw}}, \mathrm{SAR}$, and ESP were reduced only by 6.3, 5.1, and 9.9\% (Figure 5). Nevertheless, $\mathrm{EC}_{\mathrm{Sw}}$, SAR, and ESP were maintained near or below the respective threshold levels with RW irrigation. Blending and cyclic treatments had much lower values compared to RW irrigation (results not shown).

Average $\mathrm{EC}_{\mathrm{sw}}$ reductions in the $30-60 \mathrm{~cm}$ soil depth by the $0.3,0.4$, and $0.5 \mathrm{LFs}$ with $\mathrm{B}$ water irrigation were observed to be $7.3,12.5$, and $16.4 \%$, respectively, compared to the 0.2 LF (Figure 6). Similarly, average SAR and ESP reductions by the $0.5 \mathrm{LF}$ were 18.4 and $15.5 \%$, respectively. This has reduced $\mathrm{EC}_{\mathrm{Sw}}$ and $\mathrm{SAR}$ for $\mathrm{B}$ water below or near the threshold values of $4.2 \mathrm{dS} / \mathrm{m}$ and 4, respectively. However, ESP values (average ESP $=15.7$ ) were still higher and fall into the highly sodic class [58]. This may result from the precipitation of added $\mathrm{Ca}$ as gypsum in this depth of calcareous soils. As expected, $\mathrm{EC}_{\mathrm{sw}}, \mathrm{SAR}$, and ESP values were relatively higher for RW irrigation than for blending. 


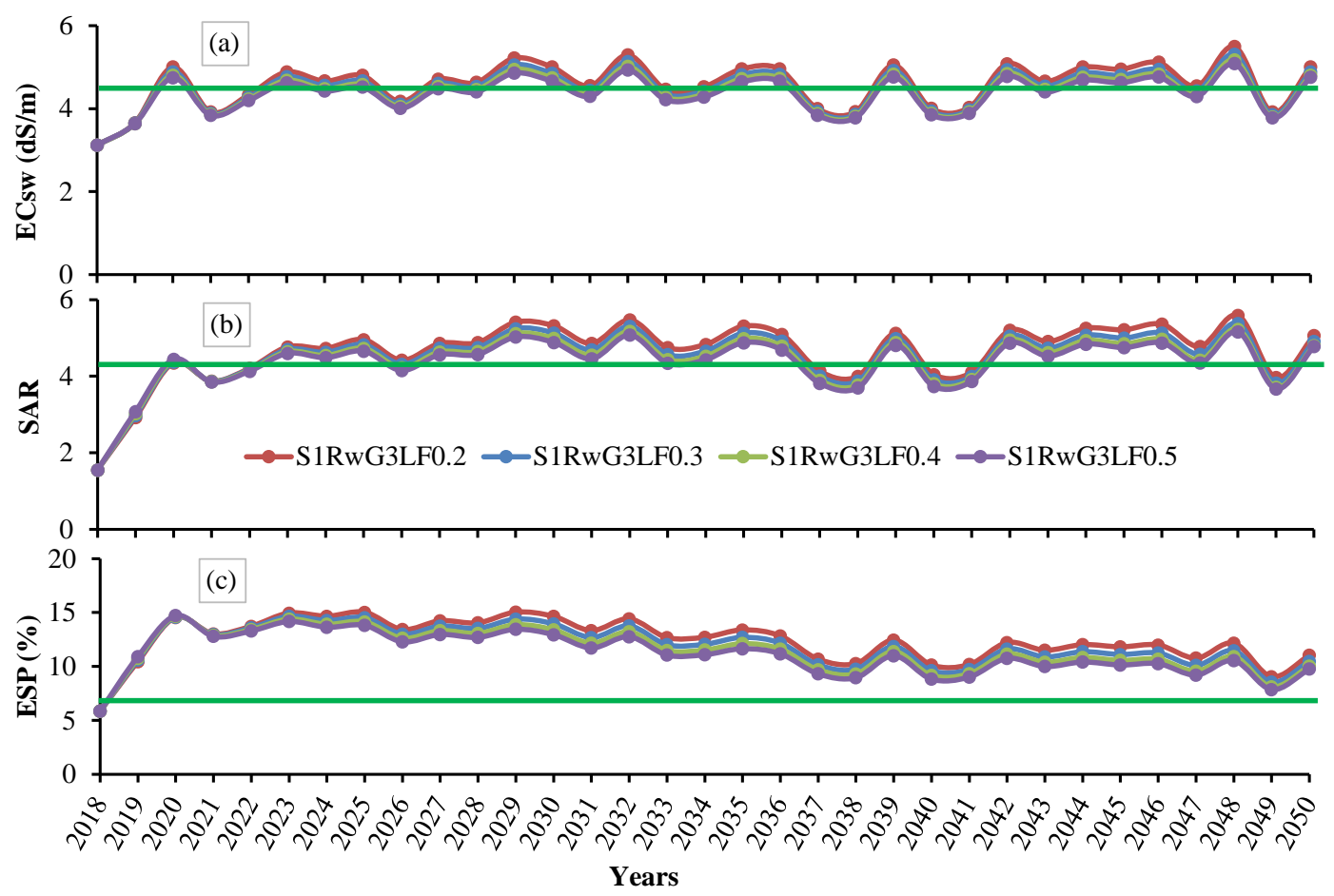

Figure 5. Impact of different leaching fractions (LF0.2, LF0.3, LF0.4, and LF0.5) and annual gypsum applications of 8.6 t/ha (G3) on (a) $\mathrm{EC}_{\mathrm{Sw}}$, (b) SAR, and (c) ESP in the 0-15 cm soil layer of the calcareous soil (S1) under recycled water (RW) irrigation of wine grapes.

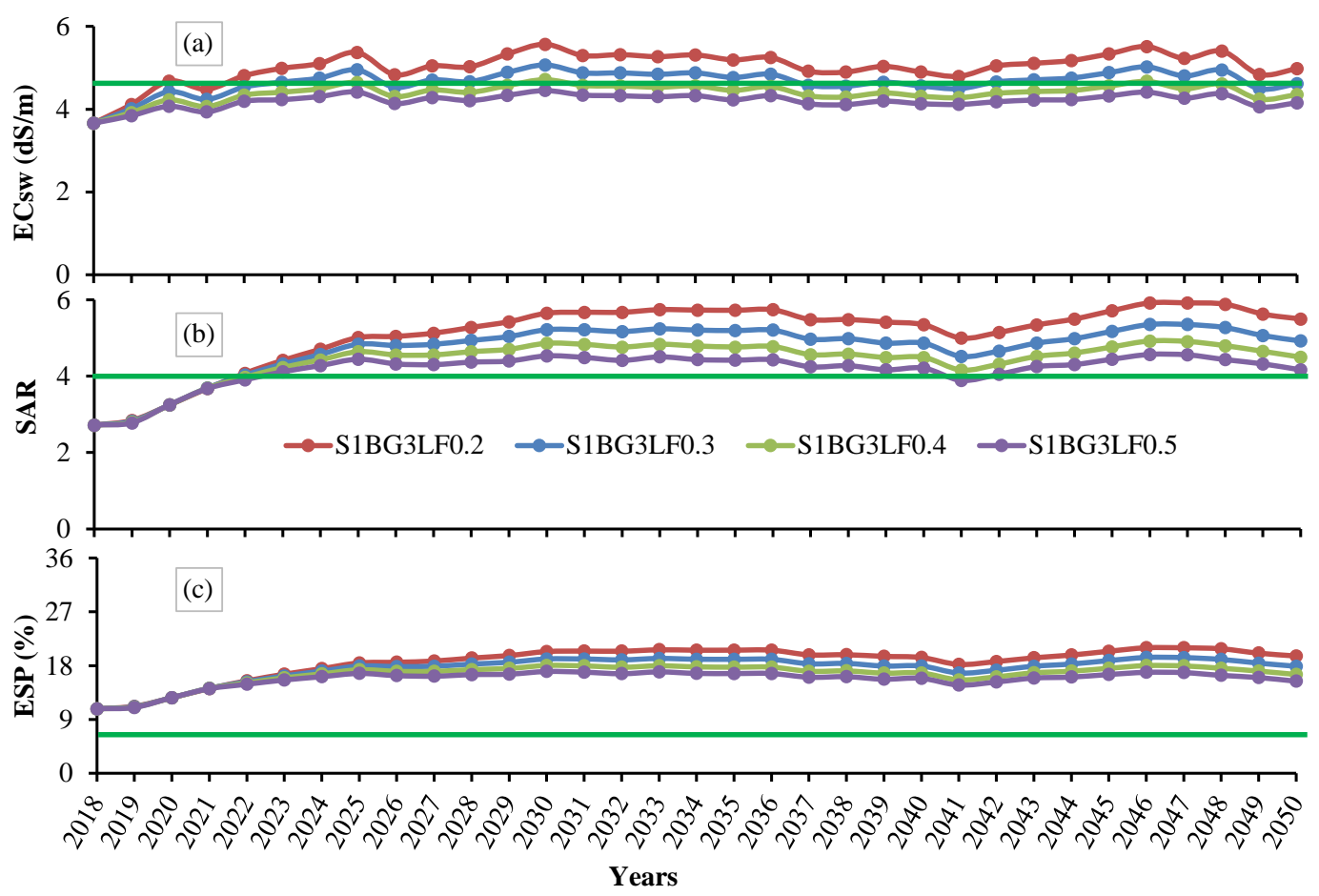

Figure 6. Impact of different leaching fractions (LF0.2, LF0.3, LF0.4, and LF0.5) and annual gypsum applications of 8.6 t/ha (G3) on (a) $\mathrm{EC}_{\mathrm{sw}}$, (b) SAR, and (c) ESP in the 30-60 cm soil layer of the calcareous soil (S1) under a 1:1 blend of recycled (RW) and good water (GW) irrigation of wine grapes.

Similarly, in the 90-120 cm soil depth, EC $\mathrm{sw}_{\mathrm{s}}$, SAR, and ESP reductions for the $0.5 \mathrm{LF}$ with B water irrigation were 21.2, 14.3, and 11\%, respectively (Figure 7). In this scenario, 
average $\mathrm{EC}_{\mathrm{Sw}}$ and SAR were reduced to $5.5 \mathrm{dS} / \mathrm{m}$ and 5.4, respectively. However, ESP was still maintained at an average value of $20.1 \%$, which falls into the highly sodic class [59] for medium- and high-tolerance crop groups [49]. $\mathrm{EC}_{\mathrm{sw}}$ and SAR values are marginally higher than the wine grape threshold, but other more tolerant crops such as pistachios and barley can be grown very well under such conditions. Organic matter additions, such as compost, could further lower harmful impacts of high ESP, enabling the use of blending or cycling of RW and GW as sustainable management options for crop production in calcareous soils. However, continuous and indiscriminate use of recycled water, especially for growing salinity-sensitive crops, should be avoided in these soils.

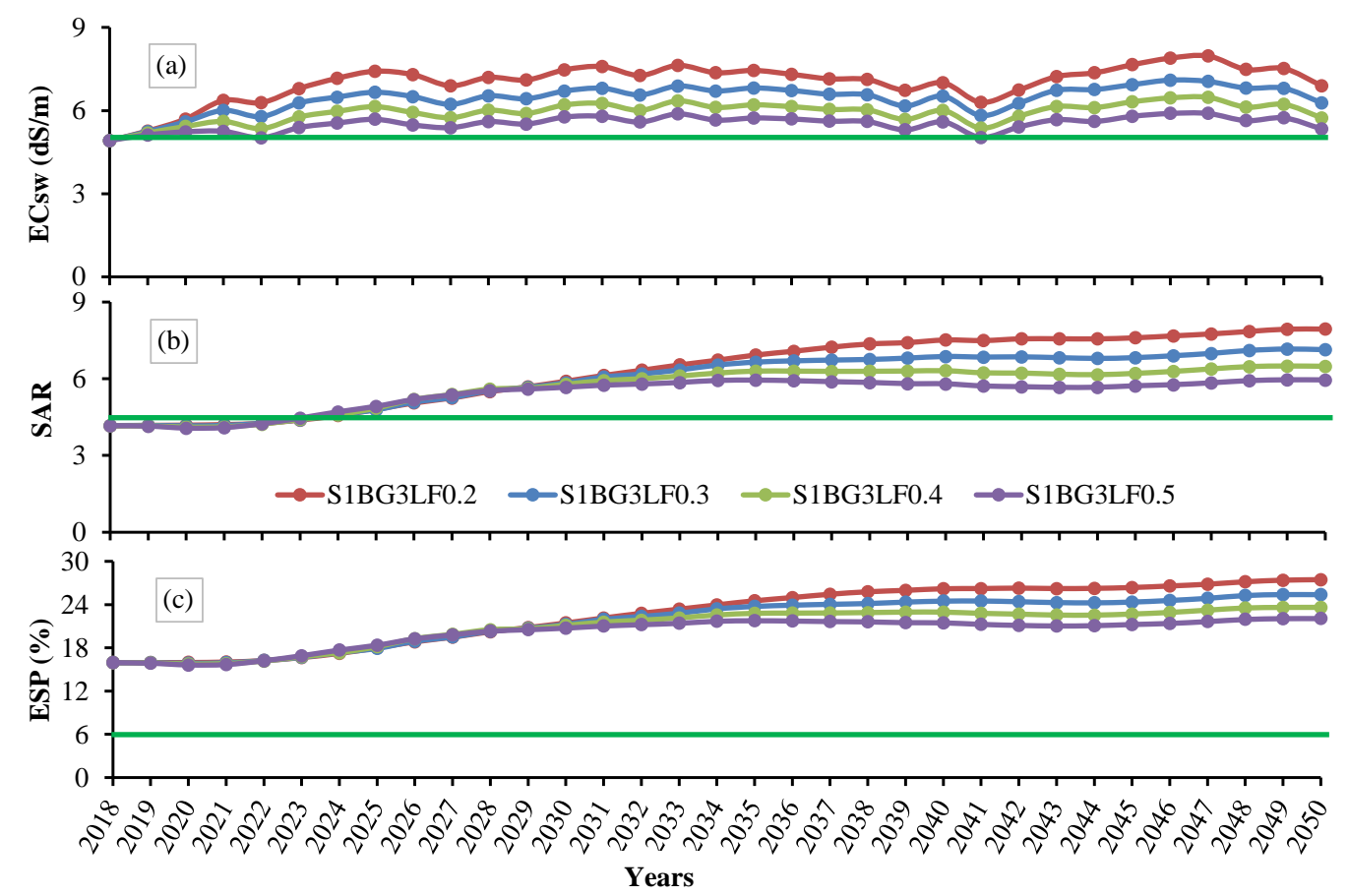

Figure 7. Impact of different leaching fractions (LF0.2, LF0.3, LF0.4, and LF0.5) and annual gypsum applications of 8.6 t/ha (G3) on (a) $\mathrm{EC}_{\mathrm{sw}}$, (b) SAR, and (c) ESP in the 90-120 cm soil layer in the calcareous soil (S1) under a 1:1 blend of recycled (RW) and SA water (GW) irrigation of wine grapes.

\subsection{Management Options in the Hard Red-Brown (HRB) Soil}

\subsubsection{Changes in Soil $\mathrm{pH}$}

In hard red-brown soils, the average soil $\mathrm{pH}$ remained higher than 8 for all irrigation treatments without gypsum additions (Figure 8). Under $\mathrm{RW}$ irrigation, $\mathrm{pH}$ values increased with depth and ranged from 8.0 to 8.4. Stevens et al. [25] also reported similar $\mathrm{pH}$ values and trends in the NAP soils irrigated with recycled water from the Bolivar plant. However, in all other treatments, reverse trends were observed, and average $\mathrm{pH}$ values varied from 8.0 to 8.3 , similar to those observed for RW irrigation. Stevens et al. [25] also reported insignificant impacts of different irrigation water qualities on soil $\mathrm{pH}$. However, gypsum applications were found to significantly impact soil $\mathrm{pH}[92,93]$, which is also visible in the present study. Annual additions of $1.7 \mathrm{t} / \mathrm{ha}$ of gypsum reduced $\mathrm{pH}$ below 8 , irrespective of irrigation water quality. The $\mathrm{pH}$ reduction (1.9-3.9\%) was much higher for gypsum additions of $1.72 \mathrm{t} / \mathrm{ha}$. Further gypsum additions resulted in gradually smaller $\mathrm{pH}$ reductions. $\mathrm{pH}$ values for annual gypsum applications of $8.6 \mathrm{t} /$ ha were almost similar to those for $12.9 \mathrm{t} / \mathrm{ha}$ applications. The reduction in $\mathrm{pH}$ varied from $5 \%$ to $6.2 \%$ as compared to the zero gypsum application. 

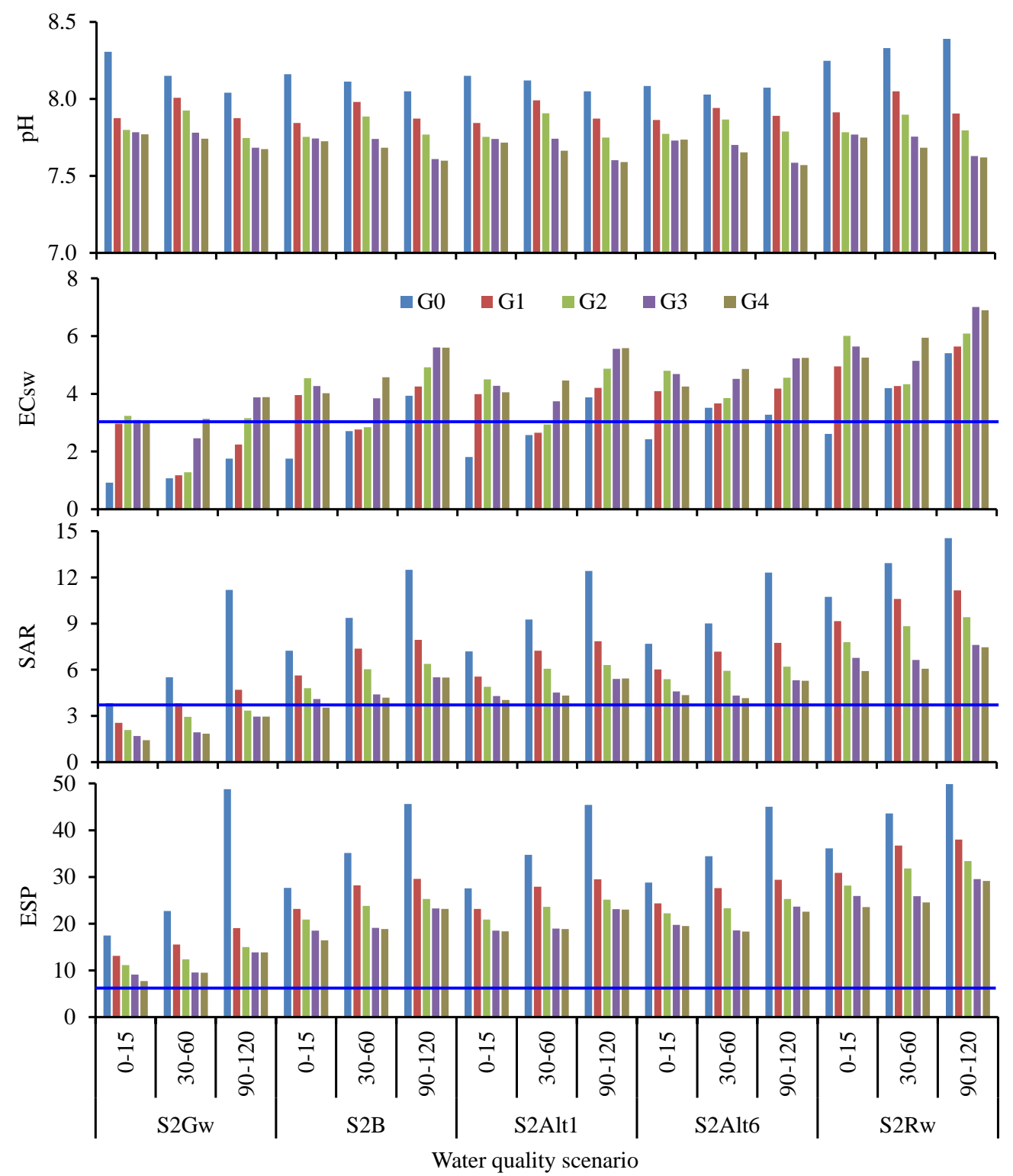

Figure 8. Average values of $\mathrm{pH}, \mathrm{EC}_{\mathrm{sw}}, \mathrm{SAR}$, and $\mathrm{ESP}$ in hard red-brown soils (S2) for different water qualities (recycled water, RW; good water, GW; blending RW and GW in a 1:1 ratio, B; RW and GW used in monthly cycles, Alt1; R and GW used half-yearly cycles, Alt6) and annual gypsum additions of 0 (G0), 1.7 (G1), 4.3 (G2), 8.6 (G3), and 12.9 (G4) t/ha.

\subsubsection{Salinity Distribution in the Soil}

Average $\mathrm{EC}_{\mathrm{sw}}$ values in scenarios without gypsum applications were observed to remain below the almond threshold salinity $\left(\mathrm{EC}_{\mathrm{sw}}=3 \mathrm{dS} / \mathrm{m}\right)$ in the $0-15 \mathrm{~cm}$ soil depth (Figure 8). However, $\mathrm{EC}_{\mathrm{SW}}$ increased in deeper depths, especially for RW irrigation, for which average values reached 4.2 and $5.4 \mathrm{dS} / \mathrm{m}$ in the $30-60$ and $90-120 \mathrm{~cm}$ depths, respectively. These values are comparable to the values for sensitive crops as reported in the Australian water quality guidelines [49]. Similarly, average $\mathrm{EC}_{\mathrm{sw}}$ in deeper depths were higher than the threshold, except for irrigation with GW water. However, annual additions of gypsum in the $0-15 \mathrm{~cm}$ soil depth rapidly increased soluble salt contents in this layer. It must be noted that gypsum is a salt with moderate solubility $(2-2.5 \mathrm{~g} / \mathrm{L})$ and, therefore, its addition increased the total soluble salt contents in the soils. It can be seen that $\mathrm{EC}_{\mathrm{sw}}$ for the scenario with $1.7 \mathrm{t} / \mathrm{ha}$ of gypsum additions and GW irrigation increased three times $(2.97 \mathrm{dS} / \mathrm{m})$ in the $0-15 \mathrm{~cm}$ layer. Similarly, in other treatments, there were considerable 
increases in the soluble salt content in the upper soil layer. However, the impact of annual gypsum additions of 1.7 and $4.3 \mathrm{t} / \mathrm{ha}$ was almost negligible in deeper depths.

A further increase in annual gypsum additions to rates of 8.6 and $12.9 \mathrm{t} /$ ha resulted in an increase in $\mathrm{EC}_{\mathrm{sw}}$ in deeper depths as well. This suggests that most gypsum added up to a rate of $4.3 \mathrm{t}$ /ha gradually solubilized and contributed to sodic soil reclamation, even though its effects on conditions in deeper soil layers were limited. However, a subsequent increase in annual gypsum additions (8.6 and $12.9 \mathrm{t} / \mathrm{ha}$ ) provided extra amounts of dissolved calcium, which gradually leached to deeper soil layers and increased the salt content there as well. Nonetheless, $\mathrm{EC}_{\mathrm{sw}}$ at the shallowest depth $(0-15 \mathrm{~cm})$ showed a decreasing trend with higher gypsum additions under almost all water quality scenarios. This indicates that the soil has reached its full capacity for gypsum solubilization in this layer.

Yearly fluctuations in $\mathrm{EC}_{\mathrm{sw}}$ in the 0-15,30-60, and 90-120 cm soil depths for different water quality scenarios with annual gypsum additions of $8.6 \mathrm{t} /$ ha are shown in Figure 9. Except for GW irrigation in the $0-15$ and $30-60 \mathrm{~cm}$ depths, $\mathrm{EC}_{\mathrm{sw}}$ was higher than the almond (a sensitive crop) tolerance threshold $\left(\mathrm{EC}_{\mathrm{sw}}=3 \mathrm{dS} / \mathrm{m}\right.$; [94]) under other water quality scenarios. Gypsum applications increased soluble salt contents in the soils. However, $\mathrm{EC}_{\mathrm{sw}}$ values were less than $6 \mathrm{dS} / \mathrm{m}$ in all soil depths, which is approximately equivalent to $\mathrm{EC}_{\mathrm{e}}$ of $3 \mathrm{dS} / \mathrm{m}$. This soil salinity level is lower than the normally accepted $\mathrm{EC}_{\mathrm{e}}$ value for saline soils [87]. $\mathrm{EC}_{\mathrm{sw}}$ also increased in response to the relative composition of irrigation water, being higher for RW irrigation in all depths. Increases in soil salinity are often associated with wastewater irrigation $[23,25,86]$ and can directly affect crop performance and many biological, chemical, and physical properties of the soil $[25,95]$. Soil profile normally attains a quasi-steady state in 3-5 years in response to different qualities of irrigation water and subsequent changes are associated with annual rainfall.

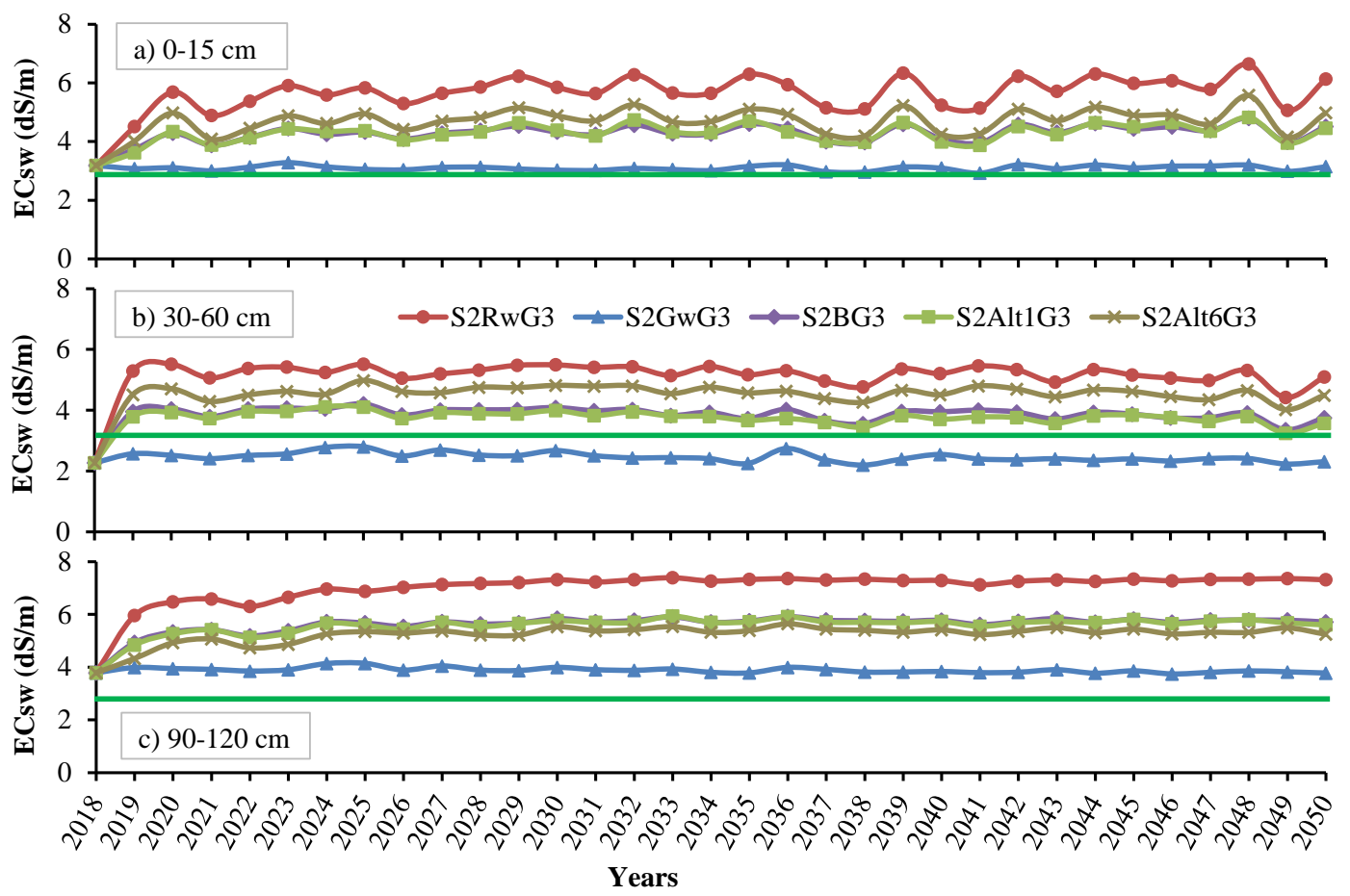

Figure 9. Impact of different water qualities (recycled water, RW; good water, GW; blending of RW and GW in a 1:1 ratio, B; RW and GW used in monthly cycles, Alt1; and RW and GW used half-yearly cycles, Alt6) and annual gypsum applications of $8.6 \mathrm{t} / \mathrm{ha}(\mathrm{G} 3)$ on $\mathrm{EC}_{\mathrm{sw}}$ for hard red-brown soil (S2) under almond cultivation.

\subsubsection{Dynamics of the Sodium Adsorption Ratio (SAR) in the HRB Soil}

Average SAR in the hard red-brown soil in the $0-15 \mathrm{~cm}$ soil depth under RW irrigation without gypsum additions was almost three times higher than under GW irrigation 
(Figure 8). However, SAR increased under GW irrigation as well, by $44 \%$ in the $30-60 \mathrm{~cm}$ depth and threefold in the 90-120 cm soil depth. The corresponding SAR values for these depths under RW irrigation were 12.9 and 14.8, respectively. Similarly, in other irrigation scenarios, including blending (B) and cycled use (Alt1 and Alt6) of GW and RW, SAR values were in between the two extremes discussed above and showed patterns with depth similar to RW and GW. However, SAR values for all water quality scenarios were higher than the threshold $(S A R=3.5)$ for the hard red-brown soil [12]. On the other hand, gypsum additions produced a considerable reduction in SAR values in all depths. A gypsum application rate of $1.7 \mathrm{t} / \mathrm{ha}$ (G1) reduced SAR by $14.7-33.5 \%, 18-30.1 \%$, and $23.2-58.1 \%$ in the 0-15, 30-60, and 90-120 cm depths in different scenarios, respectively (Figure 8). Overall, there was a SAR reduction of 28.3, 40.7, 52.0, and 54.3\% for annual gypsum applications of $1.7,4.3,8.6$, and $12.9 \mathrm{t} / \mathrm{ha}$, respectively, irrespective of the irrigation water. This shows that the reduction in SAR stabilized at annual gypsum applications of $8.6 \mathrm{t} / \mathrm{ha}$, and higher annual applications may not be economical. In addition, annual gypsum applications of $12.9 \mathrm{t}$ / ha produced only a moderate reduction (0.2-5.8\%) in SAR in all the scenarios and in all soil depths.

Annual SAR values remained higher than the threshold (3.5) for the hard red-brown soil in all depths for annual gypsum applications of $8.6 \mathrm{t} / \mathrm{ha}$ in all water quality scenarios, except for GW irrigation (Figure 10). For RW irrigation, SAR was reduced to 6 in the 30-60 cm depth, while it attained an annual value of 4.5 in blending and alternate use of GW and RW scenarios. Similarly, annual SAR was reduced to 9, 6, and 6 under RW, $\mathrm{B}$, and Alt treatments in the $90-120 \mathrm{~cm}$ depth, respectively. Constant SAR values (quasisteady state) in the 30-60 and 90-120 cm depths were attained after 6 and 10 years of irrigation, respectively (Figure 10). However, these values can still pose a serious threat to developing high ESP in the hard red-brown soil. Conversely, these values are comparable to the values for sensitive crops reported in the Australian water quality guidelines [49]. However, Suarez et al. [95] demonstrated that an increase in irrigation water SAR from 2 to 4 significantly decreased infiltration rates in clay soils. Lower infiltration rates would result in higher surface runoff during rainfall events, leading to less water availability for crops and ultimately lower crop yields.

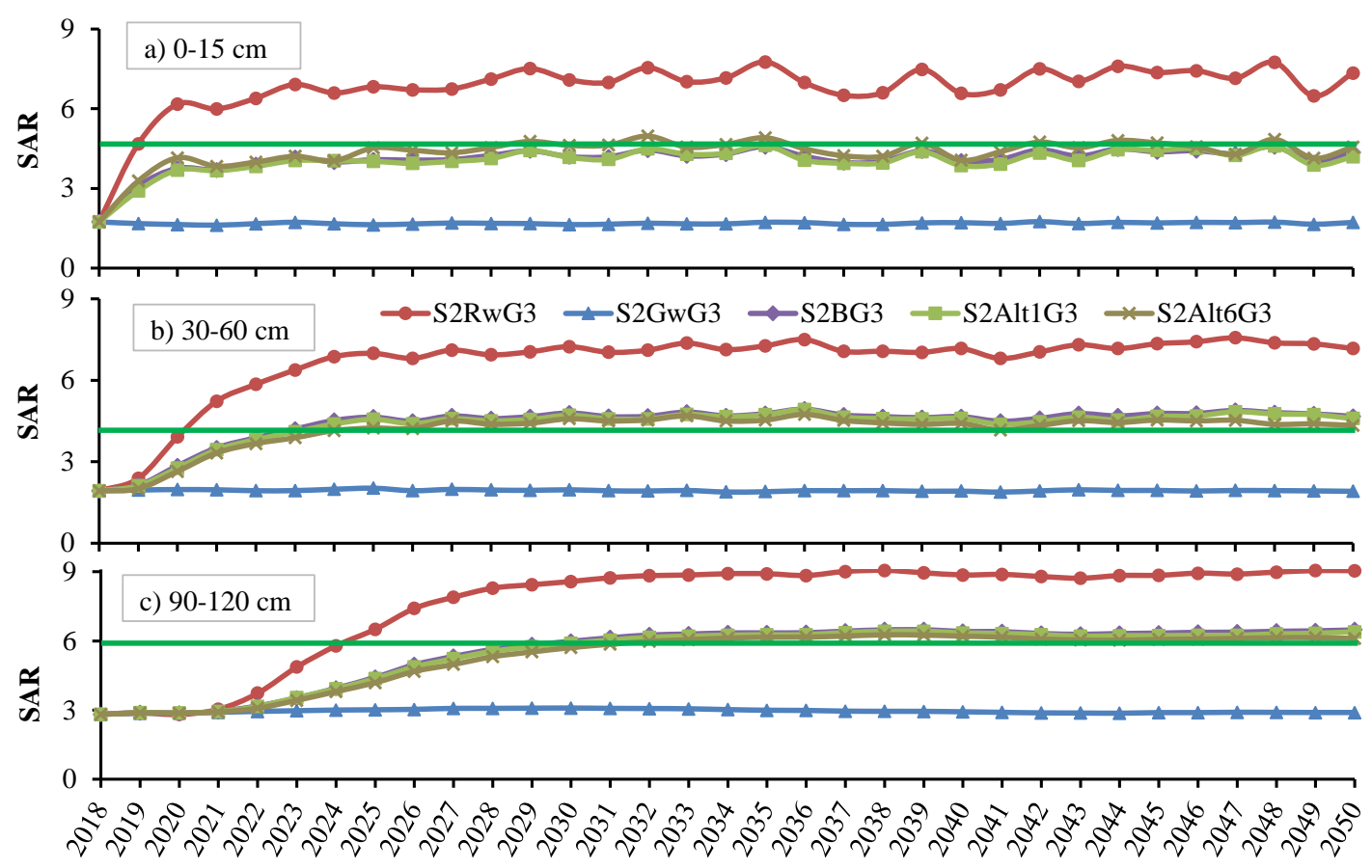

Figure 10. Impact of different water qualities (recycled water, RW; good water, GW; blending of RW and GW in a 1:1 ratio, B; RW and GW used in monthly cycles, Alt1; and RW and GW used half-yearly cycles, Alt6) and annual gypsum applications of $8.6 \mathrm{t} / \mathrm{ha}$ (G3) on annual SAR for hard red-brown soil (S2) under almond cultivation. 
Almond is extremely sensitive to SAR in the range of 2-8 [49] under non-saline conditions. These conditions can lead to leaf tip burn, and leaf scorch can have an immense impact on the tree growth and kernel yield. However, increased levels of soluble salts can help in reducing the harmful impact of high SAR. SAR of 6-10 and $\mathrm{EC}_{\mathrm{Sw}}$ of $1.87 \mathrm{dS} / \mathrm{m}$ (RW) can lead to moderate to high sodicity hazards, depending on soil texture and rainfall trends. Heavy textured soils, such as the hard red-brown soil, can develop high sodicity hazards and create considerable management issues for sustainable production.

\subsubsection{Exchangeable Sodium Percentage (ESP) in the HRB Soil}

Similarly, average ESP values in the $0-15 \mathrm{~cm}$ soil depth for scenarios without gypsum additions ranged from $17.5 \%$ to $36.1 \%$, being higher under RW irrigation and lower under GW irrigation (Figure 8). Average ESP values were within this range for blending and alternate use of RW and GW scenarios. Overall, in the 30-60 and 90-120 cm depths, ESP values increased by 24 and $70.5 \%$, respectively, as compared to the surface layer. Usually, ESP in the 90-120 cm depth was more than $45 \%$ higher under all irrigation scenarios. Hulugalle et al. [30] found that wastewater irrigation increased exchangeable $\mathrm{Na}$ in all depths. This indicates significant sodicity and associated inherent subsoil hydraulic constraints in deeper depths in the hard red-brown soil. However, average ESP values were reduced by $27,37,45$, and $47 \%$ with annual gypsum additions at a rate of $1.7,4.3,8.6$, and $12.9 \mathrm{t} / \mathrm{ha}$, respectively, irrespective of water quality and soil depth, indicating a gradual decrease in the ESP reduction with gypsum dose (Figure 8). Nevertheless, ESP values indicated highly sodic conditions (ESP > 15\%), especially in the middle $(30-60 \mathrm{~cm}$ ) and deeper $(90-120 \mathrm{~cm})$ depths. The exception is under GW irrigation, where the maximum effectiveness of gypsum applications in reducing ESP occurred in all depths. This suggests that along with gypsum, water quality plays a critical role in reducing sodic conditions.

Annual ESP values, though reduced by annual gypsum applications ( $8.6 \mathrm{t} / \mathrm{ha})$, are still higher than the critical threshold value of 6 for Australian soils in all irrigation scenarios and in all soil depths (Figure 11). Constant ESP values of 9, 9, and 14 occur in the 0-15, 3060 , and $90-120 \mathrm{~cm}$ depths, respectively, under GW irrigation. However, corresponding ESP values doubled and tripled, respectively, for scenarios with blending (B) and cyclic use (Alt1 and Alt6) and RW in all depths compared to GW irrigation. Therefore, only some shallowrooted crops can be grown with appropriate annual gypsum applications (8.6 t/ha soil) and good-quality water. All other water qualities are likely to create salinity and sodicity problems at the soil surface, as well as in deeper soil layers. Soil profile normally attains a quasi-steady state ESP in 5-10 years in response to different qualities of irrigation water and subsequent changes are associated with the variability in the annual rainfall. In fact, RW irrigation could induce severe salinity and sodicity conditions for almonds and other sensitive crops. These issues are not fully addressed by annual gypsum applications for ameliorating sodic soil conditions. However, annual gypsum applications of $8.6 \mathrm{t} / \mathrm{ha}$ reduced the soil ESP by more than half. High ESP leads to a decline of soil physical properties, in the form of clay dispersion, with the subsequent collapse of soil structure, pore blockage, and eventually a decrease in soil permeability, leading to waterlogging, poor plant performance, decreased leaching, and salinization. Brady and Weil [96] reported that for successful irrigation with reclaimed water, the saturated hydraulic conductivity $\left(\mathrm{K}_{s}\right)$ should ideally be in the range of $1-15 \mathrm{~cm} / \mathrm{h}$. Intensive irrigation with treated wastewater in loam and clay soils was shown to result in a significant increase in clay dispersion and eluviation from the upper soil layers [37]. These results corroborate the usefulness of UNSATCHEM for simulating salinity and sodicity hazards of long-term use of RW water for irrigation and predicting the amelioration by gypsum use as shown in other studies [81,97]. 


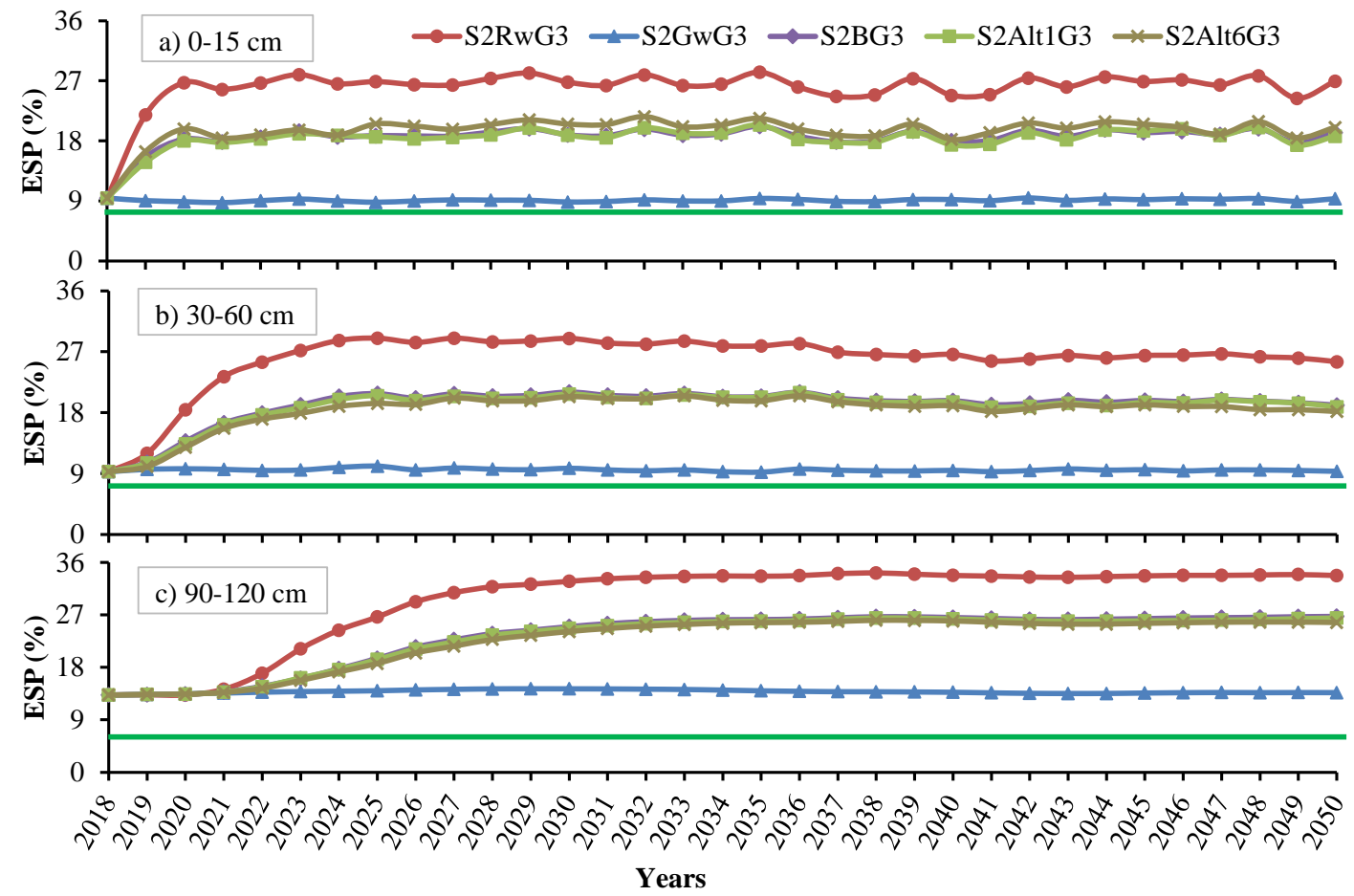

Figure 11. Impact of different water qualities (recycled water, RW; good water, GW; blending of RW and GW in a 1:1 ratio, B; RW and GW used in monthly cycles, Alt1; and RW and GW used in half-yearly cycles, Alt6) and annual gypsum applications of $8.6 \mathrm{t} / \mathrm{ha}$ (G3) on annual ESP for hard red-brown soil (S2) under almond cultivation.

\subsubsection{Role of Leaching for Salinity Control}

Long-term modelling simulations were conducted to evaluate the impact of different leaching fractions $(0.2,0.3,0.4$, and 0.5$)$ on reducing salinity and sodicity hazards in the HRB soil (Figure 12). It can be observed that relative average reductions in $\mathrm{EC}_{\mathrm{sw}}, \mathrm{SAR}$, and ESP under RW irrigation were significantly higher in all depths compared to calcareous soils because the amount of water used for irrigation of almonds grown in the HRB soil was three times higher compared to irrigation of wine grapes in the Cal soil. In the $0-15 \mathrm{~cm}$ soil depth, average reductions of $\mathrm{EC}_{\mathrm{sw}}, \mathrm{SAR}$, and ESP at the $0.5 \mathrm{LF}$ of RW irrigation were $16.9,19.3$, and $12.1 \%$, respectively (Figure 12 ). Therefore, average $\mathrm{EC}_{\mathrm{sw}}, \mathrm{SAR}$, and ESP attained values of $4.7 \mathrm{dS} / \mathrm{m}, 5.5$, and $22.8 \%$, respectively, under RW irrigation. This extent of salinity and SAR may not create any problems for tolerant crops but can reduce the yield for sensitive crops.

On the other hand, the blending option with the $0.5 \mathrm{LF}$ reduced $\mathrm{EC}_{\mathrm{sw}}$ to $3.55 \mathrm{dS} / \mathrm{m}$ and SAR to 3.3 in the $0-15 \mathrm{~cm}$ depth, which are comparable values to the almond thresholds (Figure 13). ESP was reduced to an average value of $16.3 \%$, which is higher than the lower limit for highly sodic (ESP > 15\%) conditions. Meanwhile, in the 30-60 cm depth, the blending (B) option with the $0.5 \mathrm{LF}$ reduced the average $\mathrm{EC}_{\mathrm{sw}}$ and SAR to $1.96 \mathrm{dS} / \mathrm{m}$ and 3.4, respectively, showing a positive impact of leaching (Figure 14). It is interesting to note that these values are well below the sensitive crop thresholds, including almonds. However, the average ESP was maintained at $15.7 \%$, slightly lower than the corresponding value at the surface depth. Reductions in $\mathrm{EC}_{\mathrm{sw}}, \mathrm{SAR}$, and ESP in the $30-60 \mathrm{~cm}$ soil depth ranged from 3.4-60.4, 15.5-30.4, and 12.7-26.9\%, respectively, with corresponding mean values of $49.0,22.0$, and $17.9 \%$, respectively, compared to the $0.2 \mathrm{LF}$ (Figure 14). 


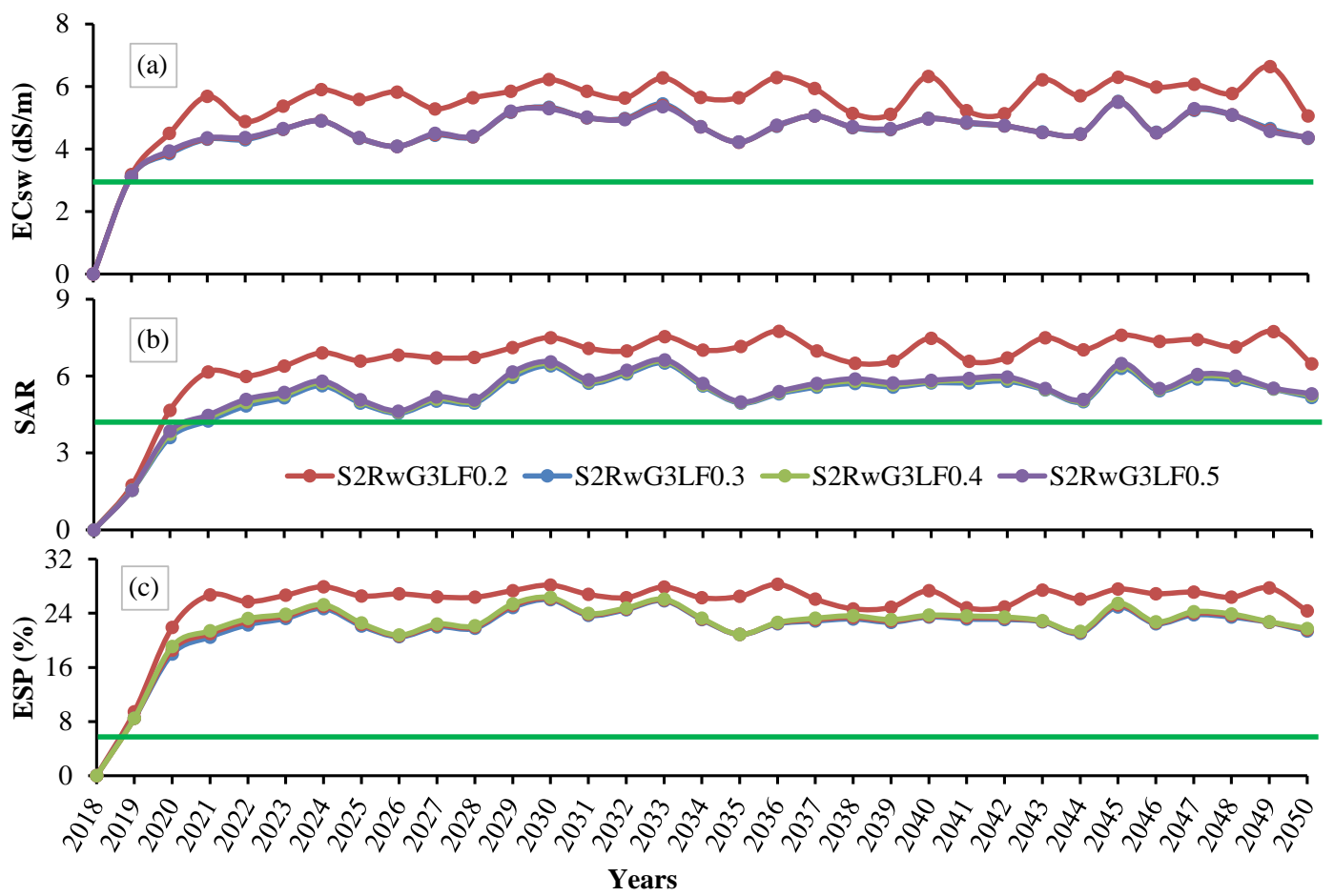

Figure 12. Impact of different leaching fractions (LF0.2, LF0.3, LF0.4, and LF0.5) and annual gypsum applications of 8.6 t/ha (G3) on (a) $\mathrm{EC}_{\mathrm{sw}}$, (b) SAR, and (c) ESP in the 0-15 cm soil layer of the hard red-brown soils (S2) under recycled water (RW) irrigation of almonds.

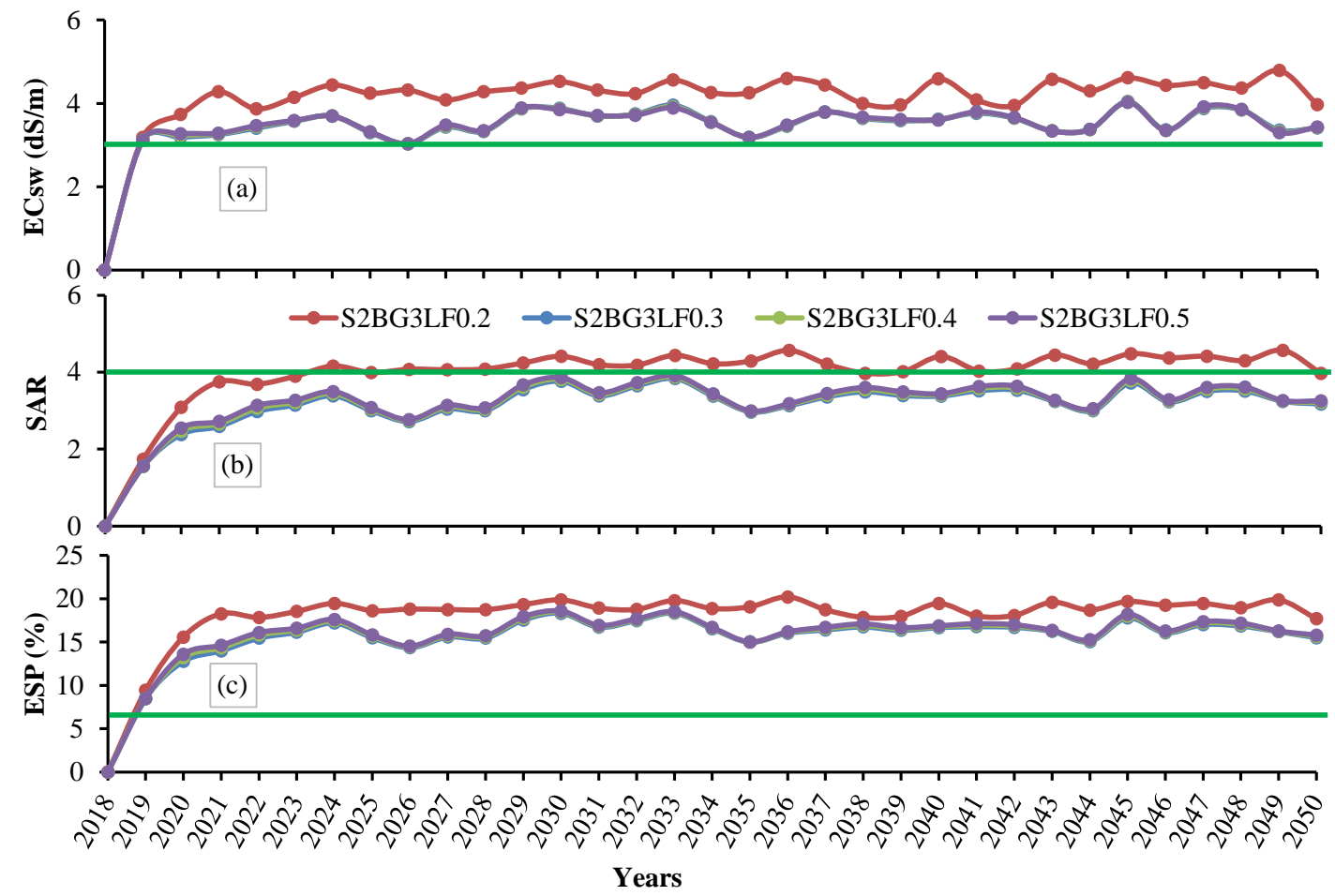

Figure 13. Impact of different leaching fractions (LF0.2, LF0.3, LF0.4, and LF0.5) and annual gypsum applications of 8.6 $\mathrm{t} / \mathrm{ha}$ (G3) on (a) $\mathrm{EC}_{\mathrm{sw}}$, (b) SAR, and (c) ESP in the 0-15 cm soil layer of the hard red-brown soil (S2) under a 1:1 blend of recycled (RW) and good water (GW) irrigation of almonds. 

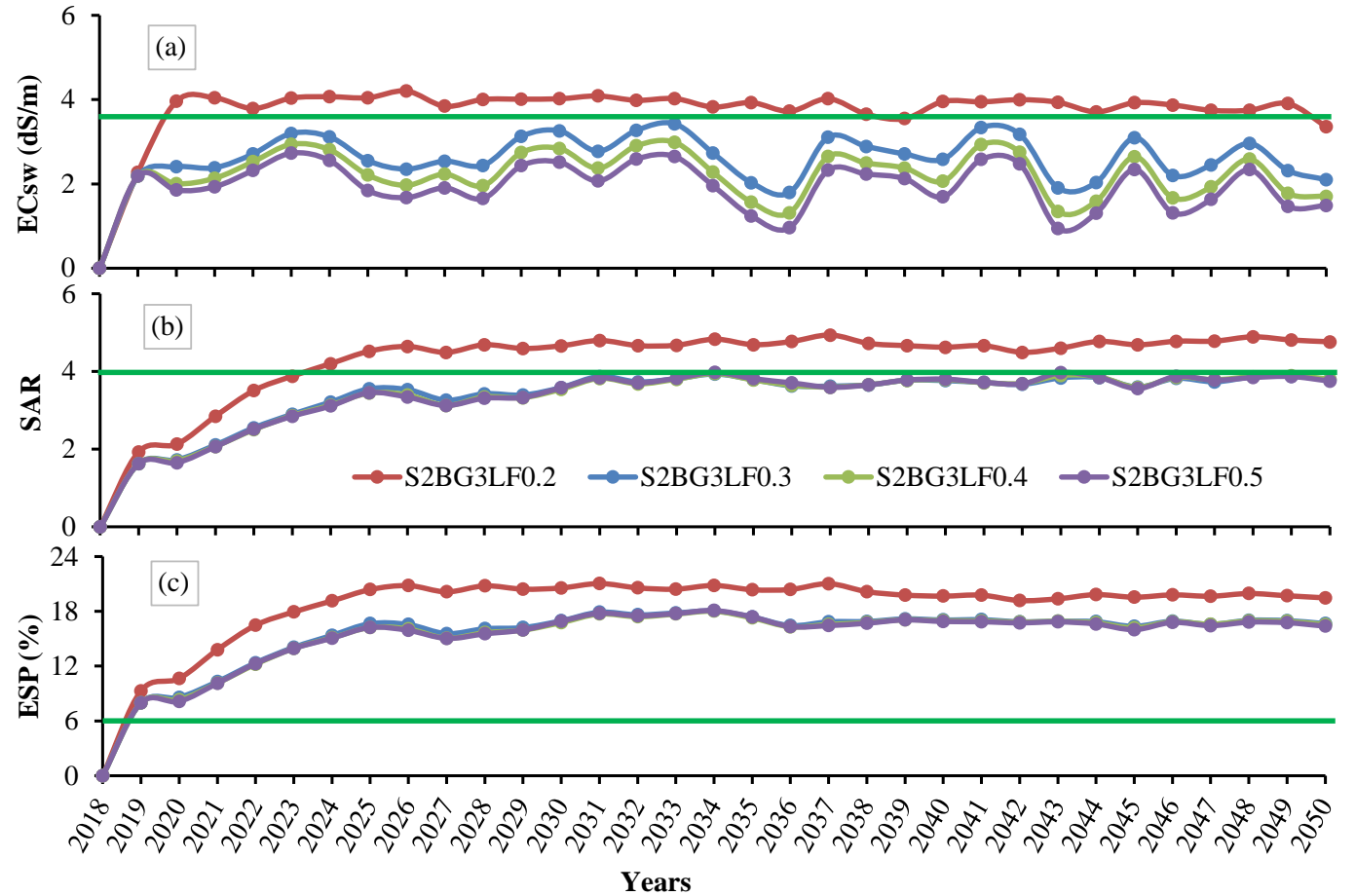

Figure 14. Impact of different leaching fractions (LF0.2, LF0.3, LF0.4, and LF0.5) and annual gypsum applications of 8.6 t/ha (G3) on (a) $\mathrm{EC}_{\mathrm{sw}}$, (b) SAR, and (c) ESP in the 30-60 cm soil layer of the hard red-brown soil under a 1:1 blend of recycled (RW) and good water (GW) irrigation of almonds.

Similarly, average values of $\mathrm{EC}_{\mathrm{sw}}, \mathrm{SAR}$, and ESP in the $90-120 \mathrm{~cm}$ depth for the $0.5 \mathrm{LF}$ with blended water were observed to be reduced by $33.1,34.8$, and $28.9 \%$, respectively, compared to the corresponding values for the 0.2 LF (Figure 15). Reading et al. [98] also reported that long-term leaching involving significantly higher pore volumes than is commonly reported in the literature is required to obtain a stable Ks in sodic clay soils. Average values of $\mathrm{EC}_{\mathrm{sw}}, \mathrm{SAR}$, and $\mathrm{ESP}$ were similar to the respective values obtained in the 30-60 cm soil depth, and ESP was still higher than the Australian classification of sodic soils. However, values are close to the ESP threshold in the US Salinity Lab classification [87]. Overall, blending RW and GW with annual gypsum applications of $8.6 \mathrm{t} / \mathrm{ha}$ coupled with the $0.5 \mathrm{LF}$ reduced the $\mathrm{EC}_{\mathrm{SW}}$ and SAR in the HRB soil to the thresholds for sensitive crops. These results are similar to Shaygan et al. [78]. They found UNSATCHEM an effective tool to simulate the salt leaching in amended sodic soils. However, ESP was maintained at a relatively higher level, creating restricted drainage/perched water table conditions if not managed appropriately. However, the harmful impacts of recycled water irrigation can be further managed with the addition of organic manures/composts, which is a common practice among growers in the NAP region.

On the other hand, a further increase in the LF $(>0.5)$ could increase the irrigation water amount to a level which would not be economically viable and which would insert immense amounts of salts into the soil, which would leach down to deeper soil layers. Ultimately, these salts can pose a serious threat to underground aquifers. Thus, immense trade-offs exist between the extent of irrigation, salts leached from the root zone, and increased risks of groundwater pollution. Apart from adopting annual gypsum applications and appropriate leaching fractions, organic matter/compost additions, and appropriate nutrient management would further help reduce the harmful impacts of constrained use of RW for sustainable crop production in the NAP region. 


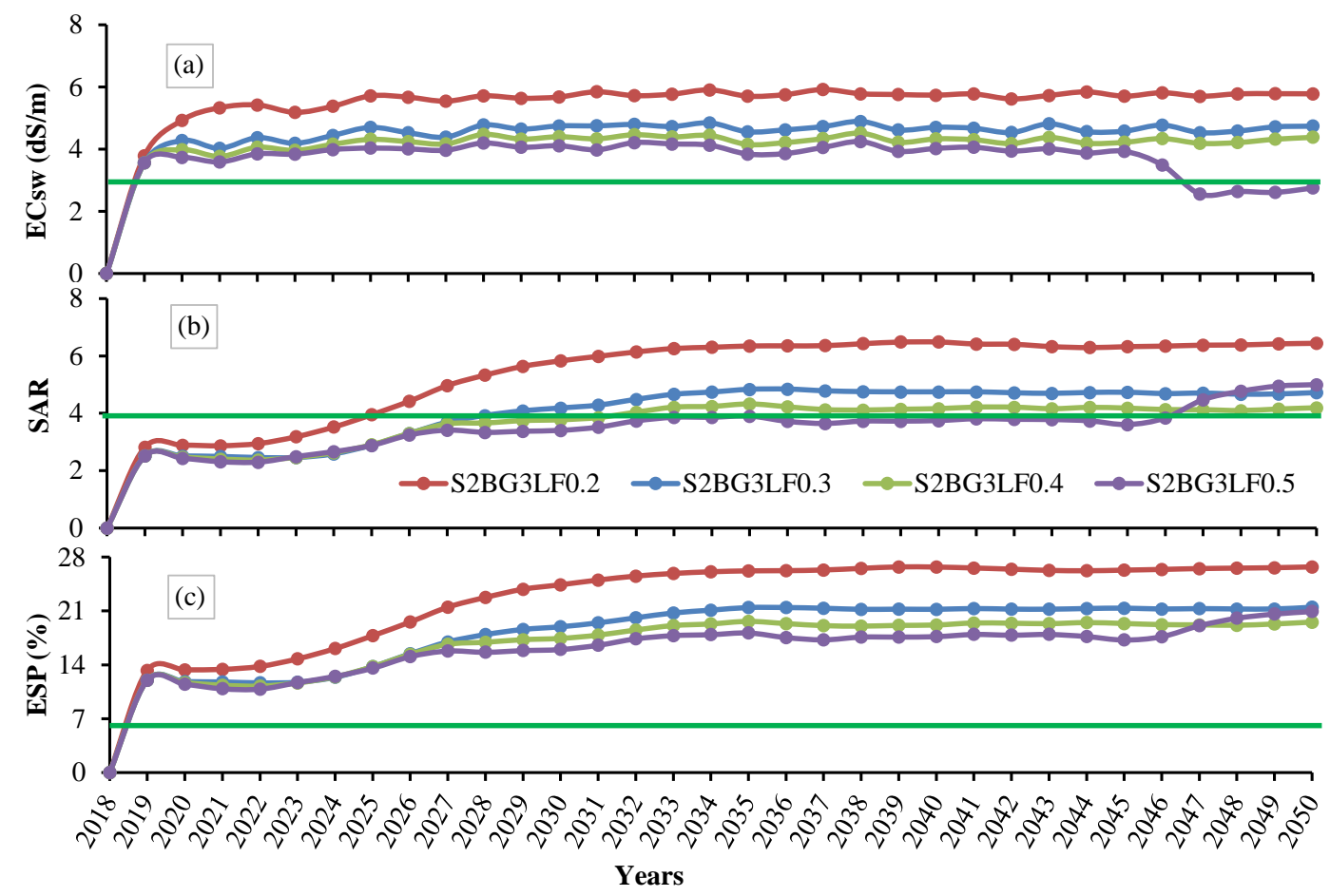

Figure 15. Impact of different leaching fractions (LF0.2, LF0.3, LF0.4, and LF0.5) and annual gypsum applications of 8.6 t/ha (G3) on (a) ECsw, (b) SAR, and (c) ESP in the 90-120 cm soil layer of the hard red-brown soil (S2) under a 1:1 blend of recycled (RW) and good water (GW) irrigation of almonds.

While it is important for any modelling study to validate the results with field observations to increase confidence in the modelling outcome, conducting long-term multifactor field studies involving varied water qualities, soil types, crops, and management options is very complex and expensive to undertake. Furthermore, the verification of predictions made into the future is not normally possible, except by commencing a long-term field trial and waiting for several years, after which a so-called retrospective study (hindcasting) can be done. If validation data are not available, model parameters and boundary conditions should be constrained as much as possible using site-specific data. This approach was adopted in the current study.

\section{Conclusions}

This modelling study evaluated the impact of long-term (2018-2050) management options involving the use of either only recycled water (RW) or RW in various combinations with good-quality water (GW), such as blending and alternate use. Management options included different leaching fractions $(0.2,0.3,0.4$, and 0.5$)$ and the annual application of varied doses of gypsum $(0,1.72,4.3,8.6$, and $12.9 \mathrm{t} / \mathrm{ha})$ to reduce salinity $\left(\mathrm{EC}_{\mathrm{sw}}\right)$ and sodicity hazards (SAR and ESP).

Results showed that the degree of salinity and sodicity problems increased manifolds in the calcareous and hard red-brown soils with the continuous use of RW irrigation. Therefore, continuous soil amelioration should be aligned with the use of RW for irrigation. Results further revealed that applying 50\% higher irrigation than leaching (LF 0.5) reduced the salinity levels below crop thresholds. Incorporating annual gypsum applications of $8.6 \mathrm{t} / \mathrm{ha}$ in calcareous and hard red-brown soils decreased SAR below the threshold $(<3)$, especially in the blending scenario and in other similar combinations (Alt1 and Alt6) of RW and GW, but not under RW alone. Combined applications of gypsum ( $8.6 \mathrm{t} / \mathrm{ha}$ ) and LF of 0.5 reduced the ESP fourfold, which demonstrated the important role of the long-term use of such ameliorants. However, reliance on a regular soil amendment with gypsum should be accompanied by a better understanding of soil water interactions, clay mineralogy, and the fate of salts, as well as the effectiveness of drainage in the soils. 
Author Contributions: Conceptualization, methodology, resources, supervision, project administration, and funding acquisition: J.W.C., D.M. and V.P.; software: J.Š. and V.P.; formal analysis: V.P.; investigation: V.P., D.M. and J.W.C.; data curation: V.P.; writing-original draft preparation: V.P.; writing-review and editing: V.P., D.M., J.Š., J.W.C., P.R.P. and T.P.; visualization: V.P. All authors have read and agreed to the published version of the manuscript.

Funding: This work was funded by the Goyder Institute for Water Research under the project "Sustainable Expansion of Irrigated Agriculture and Horticulture in Northern Adelaide Corridor (Project Number ED-17-01)".

Institutional Review Board Statement: Not applicable.

Informed Consent Statement: Not applicable.

Data Availability Statement: Modelling simulation data are available at: https:/ / doi.org/10.25919 /5d7ed23c09baa (accessed on 20 August 2021). Other data are available upon reasonable request to the corresponding authors.

Acknowledgments: Authors acknowledge the financial support by the Goyder Institute for Water Research for this work under the project "Sustainable Expansion of Irrigated Agriculture and Horticulture in Northern Adelaide Corridor (Project Number ED-17-01)".

Conflicts of Interest: The authors declare no conflict of interest.

\section{Appendix A}

Undisturbed soil cores were allowed to gradually saturate from the base upward over approximately 7 days. When samples were deemed to be fully saturated, the hydraulic conductivity was measured using the constant head method [52]. When all saturated hydraulic conductivity measurements were completed, the soil cores were disconnected from their hydraulic extensions and weighed to obtain their saturated weights. The cores were then placed onto saturated ceramic plates connected to either hanging water columns or exposed to positive gas (nitrogen) pressures in sealed chambers. The cores were exposed to sequentially increasing hydrostatic pressures ranging from saturation (nominated to be $0.1 \mathrm{kPa}$ ) to $4,8,33,60$, and $100 \mathrm{kPa}$. When equilibrium was deemed to have occurred (based upon experience and measurement), each soil core was weighed, re-saturated, and placed back onto a ceramic plate for the next pressure. After weighing the samples at $100 \mathrm{kPa}$, they were dried to a constant weight in an oven at $105^{\circ} \mathrm{C}$, then re-weighed (and the tare weight of the stainless-steel ring, mesh, and elastic band were recorded). Separate soil samples (saved from trimming each core) were used to measure the water content of the soil at $1500 \mathrm{kPa}$. To achieve this, small duplicate samples were placed directly onto the surface of saturated ceramic plates (capacity $15 \mathrm{bar}$ ) and exposed to $1500 \mathrm{kPa}$ of nitrogen gas pressure in reinforced steel chambers for 6 weeks. Water content values at different matric suctions and the saturated hydraulic conductivity were used to estimate the soil hydraulic parameters by fitting the van Genuchten-Mualem model using the RETC software. Average values of hydraulic parameters estimated for soil profiles within each textural group, as shown in Table A1, were considered in the modelling study.

Soil chemical parameters required by the UNSATCHEM module include the Gapon exchange constants, the initial concentrations of soil exchangeable cations $\left(\mathrm{K}^{+}, \mathrm{Na}^{+}, \mathrm{Ca}^{2+}\right.$, $\left.\mathrm{Mg}^{2+}\right)$, and the initial solution composition $\left(\mathrm{K}^{+}, \mathrm{Na}^{+}, \mathrm{Ca}^{2+}, \mathrm{Mg}^{2+}\right.$, alkalinity, $\left.\mathrm{SO}_{4}{ }^{2-}, \mathrm{Cl}^{-}\right)$ in the soil profile. The latter was defined using the average solution composition of RW $[10,12,48]$. The average values of $\mathrm{Ca}^{2+}, \mathrm{Mg}^{2+}, \mathrm{Na}^{+}, \mathrm{K}^{+}$, alkalinity, $\mathrm{SO}_{4}{ }^{2-}$, and $\mathrm{Cl}^{-}$in RW were $1.92,2.75,12.43,0.99,1.97,3.76$, and $11.51 \mathrm{meq} / \mathrm{L}$, respectively. Exchangeable cations were determined using the $\mathrm{NH}_{4} \mathrm{Cl}$ solution at either $\mathrm{pH} 7.0$ or $\mathrm{pH} 8.5$, depending on the soil $\mathrm{pH}$ [10]. The cation exchange capacity (CEC) was assumed to be equal to the sum of adsorbed concentrations of the four cations $\left(\mathrm{Na}^{+}, \mathrm{Ca}^{2+}, \mathrm{Mg}^{2+}\right.$, and $\left.\mathrm{K}^{+}\right)$, and it was assumed that the CEC (107.4-161.5 meq/ $\mathrm{kg}$ soil) is constant and $\mathrm{pH}$-independent. The ESP varied from $9.52-16.61 \%$, which was much higher than the threshold value $(6 \%)$ for Australian conditions. The estimation of Gapon constants for HRB and Cal soil group 
is described in [10]. Values of soil exchangeable cations and Gapon constants for both soils used in the modelling simulations are shown in Table A2. Soil chemical properties (Table A2) measured in the $0-30 \mathrm{~cm}$ soil layer were assumed to extend to $200 \mathrm{~cm}$ (the domain depth) as the soils had almost uniform texture below $20 \mathrm{~cm}$. Running the model during the warm-up period (48 years) allowed the chemical species to acquire a stable chemical composition in the solution and at the soil exchanger.

Table A1. Estimated average soil hydraulic parameters for different soil groups in the study area (from [10]).

\begin{tabular}{|c|c|c|c|c|c|c|}
\hline \multirow{2}{*}{$\begin{array}{l}\text { Soil Depth } \\
\text { (cm) }\end{array}$} & $\theta_{\mathrm{r}}$ & $\theta_{\mathrm{s}}$ & $\alpha$ & $n$ & $\mathbf{K}_{\mathrm{s}}$ & $\mathbf{L}$ \\
\hline & $\left(\mathrm{cm}^{3} \mathrm{~cm}^{-3}\right)$ & $\left(\mathrm{cm}^{3} \mathrm{~cm}^{-3}\right)$ & $\left(\mathrm{cm}^{-1}\right)$ & $(-)$ & $\left(\mathrm{cm} \mathrm{day}{ }^{-1}\right)$ & $(-)$ \\
\hline \multicolumn{7}{|c|}{ Soil Group 1: Calcareous soils (Cal) } \\
\hline $0-15$ & 0.078 & 0.48 & 0.035 & 1.239 & 207.36 & 0.5 \\
\hline $15-30$ & 0.096 & 0.482 & 0.085 & 1.208 & 181.44 & 0.5 \\
\hline $30-60$ & 0.0758 & 0.485 & 0.2781 & 1.1639 & 146.00 & 0.5 \\
\hline $60-100$ & 0.0001 & 0.481 & 0.2305 & 1.1382 & 267.79 & 0.5 \\
\hline $100-200$ & 0.0735 & 0.4087 & 0.0242 & 1.298 & 22.91 & 0.5 \\
\hline \multicolumn{7}{|c|}{ Soil Group 2: Hard red-brown soils (HRB) } \\
\hline $0-15$ & 0.073 & 0.469 & 0.025 & 1.217 & 50.11 & 0.5 \\
\hline $15-30$ & 0.101 & 0.446 & 0.059 & 1.187 & 40.61 & 0.5 \\
\hline $30-60$ & 0.109 & 0.465 & 0.282 & 1.133 & 13.98 & 0.5 \\
\hline $60-100$ & 0.1365 & 0.4588 & 0.0891 & 1.1216 & 13.33 & 0.5 \\
\hline $100-200$ & 0.0807 & 0.4112 & 0.0255 & 1.2196 & 12.82 & 0.5 \\
\hline
\end{tabular}

$\theta_{\mathrm{r}}$ is the residual water content; $\theta_{\mathrm{S}}$ represents the saturated water content; $\alpha$ represents the inverse of an air entry value; $\mathrm{n}$ and $\mathrm{L}$ are pore distribution parameters, and $\mathrm{K}_{\mathrm{s}}$ is the soil saturated hydraulic conductivity.

Table A2. The estimated initial concentrations of cations, Gapon selectivity coefficients, and soil solution compositions in different soil groups.

\begin{tabular}{|c|c|c|c|c|c|c|c|}
\hline \multirow{2}{*}{ Soil Type } & \multicolumn{4}{|c|}{ Exchangeable Cation Concentration (meq/kg) } & \multicolumn{3}{|c|}{ Gapon Coefficients } \\
\hline & Ca-X & Mg-X & $\mathrm{Na}-\mathrm{X}$ & $\mathbf{K}-\mathbf{X}$ & $\mathrm{K}_{\mathrm{Ca} / \mathrm{Na}}$ & $\mathrm{K}_{\mathrm{Ca} / \mathrm{K}}$ & $\mathrm{K}_{\mathrm{Mg} / \mathrm{Ca}}$ \\
\hline Cal & 51.87 & 35.32 & 13.71 & 7.74 & 0.038 & 0.957 & 0.009 \\
\hline \multirow[t]{3}{*}{ HRB } & 53.17 & 60.61 & 36.93 & 15.32 & 0.033 & 0.753 & 0.065 \\
\hline & \multicolumn{7}{|c|}{ Soil solution composition (meq/L) } \\
\hline & $\mathrm{Ca}^{2+}$ & $\mathrm{Mg}^{2+}$ & $\mathrm{Na}^{+}$ & $\mathrm{K}^{+}$ & Alk & $\mathrm{Cl}^{-}$ & $\mathrm{SO}_{4}^{2-}$ \\
\hline Cal & 3.82 & 2.31 & 9.91 & 0.05 & 3.22 & 0.5 & 11.3 \\
\hline HRB & 2.94 & 3.58 & 14.81 & 0.58 & 3.78 & 2.28 & 15.34 \\
\hline
\end{tabular}

Horticulture in Northern Adelaide Corridor (Project Number ED-17-01).

\section{References}

1. Qadir, M.; Wichelns, D.; Sally, L.R.; McCornick, P.G.; Drechsel, P.; Bahri, A.; Minhas, P.S. The challenges of wastewater irrigation in developing countries. Agric. Water Manag. 2010, 97, 561-568. [CrossRef]

2. Mavi, M.S.; Marschner, P.; Chittleborough, D.J.; Cox, J.W.; Sanderman, J. Salinity and sodicity affect soil respiration and dissolved organic matter dynamics differentially in soils varying in texture. Soil Biol. Biochem. 2012, 45, 8-13. [CrossRef]

3. Hanjra, M.A.; Blackwell, J.; Carr, G.; Zhang, F.; Jackson, T.M. Wastewater irrigation and environmental health: Implications for water governance and public policy. Int. J. Hyg. Environ. Health 2012, 215, 255-269. [CrossRef]

4. Hassena, A.B.; Zouari, M.; Trabelsi, L.; Khabou, W.; Zouari, N. Physiological improvements of young olive tree (Olea europaea L. cv. Chetoui) under short-term irrigation with treated wastewater. Agric. Water Manag. 2018, 207, 53-58. [CrossRef]

5. Singh, P.K.; Deshbhratar, P.B.; Ramteke, D.S. Effects of sewage waste water irrigation on soil properties, crop yield and environment. Agric. Water Manag. 2012, 103, 100-104. [CrossRef]

6. Lal, K.; Minhas, P.S.; Yadav, R.K. Long-term impact of wastewater irrigation and nutrient rates II. Nutrient balance, nitrate leaching and soil properties under peri-urban cropping systems. Agric. Water Manag. 2015, 156, 110-117. [CrossRef]

7. Minhas, P.S.; Lal, K.; Yadav, R.K.; Dubey, S.K.; Chaturvedi, R.K. Impacts of long-term irrigation with domestic sewage and nutrient rates I. Performance, sustainability and produce quality of peri-urban cropping systems. Agric. Water Manag. 2015, 156, 100-109. [CrossRef] 
8. Elfanssi, S.; Ouazzani, N.; Mandi, L. Soil properties and agro-physiological responses of alfalfa (Medicago sativa L.) irrigated by treated domestic wastewater. Agric. Water Manag. 2018, 202, 231-240. [CrossRef]

9. Minhas, P.S. Sustainable management of brackish water agriculture. In Advances in Soil Science: Soil Water and Agronomic Productivity; Lal, R., Stewart, B.A., Eds.; CRC Press: London, UK, 2012; pp. 289-323.

10. Mallants, D.; Phogat, V.; Oliver, D.; Ouzman, J.; Beirgadhar, Y.; Cox, J. Sustainable Expansion of Irrigated Agriculture and Horticulture in Northern Adelaide Corridor: Task 2; Technical Report Series No. 19/15; Goyder Institute for Water Research: Adelaide, Australia, 2019.

11. Phogat, V.; Mallants, D.; Cox, J.W.; Šimůnek, J.; Oliver, D.P.; Pitt, T.; Petrie, P.R. Impact of long-term recycled water irrigation on crop yield and soil chemical properties. Agric. Water Manag. 2020, 237, 106167. [CrossRef]

12. Phogat, V.; Mallants, D.; Cox, J.W.; Šimůnek, J.; Oliver, D.P.; Awad, J. Management of soil chemical changes associated with irrigation of protected crops. Agric. Water Manag. 2020, 227, 105845. [CrossRef]

13. Oster, J.; Sposito, G.; Smith, C.J. Accounting for potassium and magnesium in irrigation water quality assessment. Calif. Agric. 2016, 70, 71-76. [CrossRef]

14. Rengasamy, P.; Marchuk, A. Cation ratio of soil structural stability (CROSS). Soil Res. 2011, 49, 280-285. [CrossRef]

15. Laurenson, S.; Bolan, N.S.; Smith, E.; McCarthy, M. Review: Use of recycled wastewater for irrigating grapevines. Aust. J. Grape Wine Res. 2012, 18, 1-10. [CrossRef]

16. Smith, C.; Oster, J.D.; Sposito, G. Potassium and magnesium in irrigation water quality assessment. Agric. Water Manag. 2015, 157, 59-64. [CrossRef]

17. Bennett, J.M.L.; Marchuk, A.; Marchuk, S. An alternative index to the exchangeable sodium percentage for an explanation of dispersion occurring in soils. Soil Res. 2016, 54, 949-957. [CrossRef]

18. Zhu, Y.; Ali, A.; Dang, A.; Wandel, A.P.; Bennett, J.; Mc, L. Re-examining the flocculating power of sodium, potassium, magnesium and calcium for a broad range of soils. Geoderma 2019, 352, 422-428. [CrossRef]

19. Liang, X.; Rengasamy, P.; Smernik, R.; Mosley, L.M. Does the high potassium content in recycled winery wastewater used for irrigation pose risks to soil structural stability? Agric. Water Manag. 2021, 243, 106422. [CrossRef]

20. Rengasamy, P.; Sumner, M.E. Processes involved in sodic behavior. In Sodic Soil: Distribution, Management and Environmental Consequences; Sumner, M.E., Naidu, R., Eds.; Oxford University Press: New York, NY, USA, 1998; pp. 35-50.

21. Grieve, C.M.; Grattan, S.R.; Maas, E.V. Plant salt tolerance in agricultural salinity assessment and management. In ASCE Manuals and Reports on Engineering Practice No. 71, 2nd ed.; Wallender, W.W., Tanji, K.K., Eds.; American Society of Civil Engineers (ASCE): Reston, VA, USA, 2012; pp. 405-459.

22. Grattan, S.R.; Díaz, F.J.; Pedrero, F.; Vivaldi, G.A. Assessing the suitability of saline wastewaters for irrigation of Citrus spp.: Emphasis on boron and specific-ion interactions. Agric. Water Manag. 2015, 157, 48-58. [CrossRef]

23. Rengasamy, P.; Olsson, K.A. Irrigation and sodicity. Aust. J. Soil Res. 1993, 31, 821-837. [CrossRef]

24. Assouline, S.; Narkis, K. Effects of long-term irrigation with treated wastewater on the root zone environment. Vadose Zone J. 2013, 12, 1-10. [CrossRef]

25. Stevens, D.P.; McLaughlin, M.J.; Smart, M.K. Effects of long-term irrigation with reclaimed water on soils of the Northern Adelaide Plains, South Australia. Aust. J. Soil Res. 2003, 41, 933-948. [CrossRef]

26. Hoffman, G. Leaching fraction and root zone salinity control. In Agricultural Salinity Assessment; Tanji, K., Ed.; American Society Civil Engineers: New York, NY, USA, 1990; pp. 237-261.

27. Oster, J. Irrigation with poor quality water. Agric. Water Manag. 1994, 25, 271-297. [CrossRef]

28. Paudel, I.; Cohen, S.; Shlizerman, L.; Jaiswal, A.K.; Shaviv, A.; Sadka, A. Reductions in root hydraulic conductivity in response to clay soil and treated waste water are related to PIPs down-regulation in Citrus. Sci. Rep. 2017, 7, 1-14. [CrossRef]

29. Paudel, I.; Bar-Tal, A.; Levy, G.J.; Rotbart, N.; Ephrath, J.E.; Cohen, S. Treated wastewater irrigation: Soil variables and grapefruit tree performance. Agric. Water Manag. 2018, 204, 126-137. [CrossRef]

30. Hulugalle, N.R.; Weaver, T.B.; Ghadiri, H.; Hicks, A. Changes in soil properties of an eastern Australian vertisol irrigated with treated sewage effluent following gypsum application. Land Degrad. Dev. 2006, 17, 527-540. [CrossRef]

31. Levy, G.J.; Fine, P.; Goldstein, D.; Azenkot, A.; Zilberman, A.; Chazan, A.; Grinhut, T. Long term irrigation with treated wastewater (TWW) and soil sodification. Biosyst. Eng. 2014, 128, 4-10. [CrossRef]

32. Assouline, S.; Narkis, K.; Gherabli, R.; Sposito, G. Combined effect of sodicity and organic matter on soil properties under long-term irrigation with treated wastewater. Vadose Zone J. 2016, 15, 1-10. [CrossRef]

33. Qian, Y.; Lin, Y. Comparison of soil chemical properties prior to and five to eleven years after recycled water irrigation. J. Environ. Qual. 2019, 48, 1758-1765. [CrossRef]

34. Naidu, R.; Merry, R.H.; Churchman, G.J.; Wright, M.J.; Murray, R.S.; Fitzpatrick, R.W.; Zarcinas, B.A. Sodicity in South AustraliaA review. Aust. J. Soil Res. 1993, 31, 911-929. [CrossRef]

35. Rengasamy, P. Clay dispersion. In Soil Physical Measurement and Interpretation for Land Evaluation; McKenzie, B.M., Coughlan, K., Cresswell, H., Eds.; CSIRO Publishing: Melbourne, Australia, 2002; pp. 200-210.

36. Minhas, P.S.; Qadir, M.; Yadav, R.K. Groundwater irrigation induced soil sodification and response options. Agric. Water Manag. 2019, 215, 74-85. [CrossRef]

37. Warrington, D.N.; Goldstein, D.; Levy, G.J. Clay translocation within the soil profile as affected by intensive irrigation with treated wastewater. Soil Sci. 2007, 172, 692-700. [CrossRef] 
38. Nemera, D.B.; Bar-Tal, A.; Levy, G.J.; Lukyanov, V.; Tarchitzky, J.; Paudel, I.; Cohen, S. Mitigating negative effects of long-term treated wastewater application via soil and irrigation manipulations: Sap flow and water relations of avocado trees (Persea americana Mill.). Agric. Water Manag. 2020, 237, 106178. [CrossRef]

39. Minhas, P.S.; Dubey, S.K.; Sharma, D.R. Comparative effects of blending, intra/inter-seasonal cyclic uses of alkali and good quality waters on soil properties and yields of paddy and wheat. Agric. Water Manag. 2007, 87, 83-90. [CrossRef]

40. Grattan, S.R.; Rhoades, J.D. Irrigation with saline groundwater and drainage water. In Agricultural Salinity Assessment and Management; Tanji, K.K., Ed.; American Society of Civil Engineers: New York, NY, USA, 1990; pp. 432-449.

41. Stevens, R.; Harvey, G.; Partlington, D.; Coombe, B. Irrigation of grapevines with saline water at different growth stages I. effects on soil, vegetative growth, and yield. Aust. J. Agric. Res. 1999, 50, 343-355. [CrossRef]

42. Stevens, R.; Walker, R. Response of grapevines to irrigation-induced saline-sodic conditions. Aust. J. Exp. Agric. 2002, 42, 323-331. [CrossRef]

43. Maas, E.V. Salt tolerance of plants. In CRC Handbook of Plant Science in Agriculture; Christie, B.R., Ed.; CRC Press: Boca Raton, FL, USA, 1987.

44. George, M.; Pettygrove, G.; Davis, W. Crop selection and management. In Irrigation with Reclaimed Municipal Wastewater: A Guidance Manual; Pettygrove, G.S., Asano, T., Eds.; California State Water Resource Control Board: Sacramento, CA, USA, 1985.

45. Sumner, M.E.; Radcliffe, D.E.; McCray, M.; Carter, E.; Clark, R.L. Gypsum as an ameliorant for subsoil hardpans. Soil Technol. 1990, 3, 253-258. [CrossRef]

46. The Goyder Institute for Water Research. Northern Adelaide Plains Water Stocktake Technical Report; The Goyder Institute for Water Research: Adelaide, Australia, 2016.

47. Department of Environment, Water and Natural Resources. Non-Prescribed Surface Water Resources Assessment-Adelaide and Mount Lofty Ranges Natural Resources Management Region; DEWNR Technical Report 2016/34; Department of Environment, Water and Natural Resources, Government of South Australia: Adelaide, Australia, 2016.

48. Awad, J.; Vanderzalm, J.; Pezzaniti, D.; Olubukoa Esu, O.-O.; van Leeuwen, J. Sustainable Expansion of Irrigated Agriculture and Horticulture in Northern Adelaide Corridor: Source Water Options/Water Availability, Quality and Storage Consideration; Goyder Institute for Water Research Technical Report Series No. 19/16; Goyder Institute for Water Research: Adelaide, Australia, 2019.

49. ANZECC; ARMCANZ. National Water Quality Management Strategy: Australian and New Zealand Guidelines for Fresh and Marine Water Quality; Australia and New Zealand Environment and Conservation Council and Agriculture and Resource Management Council of Australia and New Zealand: Canberra, Australia, 2000; Volume 1, Chapters 1-7.

50. Oliver, D.P.; Fruzangohar, M.; Johnston, C.; Ouzman, J.; Barry, K. Sustainable Expansion of Irrigated Agriculture and Horticulture in Northern Adelaide Corridor. Task 1: Development and Optimisation of Modelling Domain and Impact Assessment of Irrigation Expansion on the Receiving Environment; Technical Report Series No. 19/14; Goyder Institute for Water Research: Adelaide, Australia, 2019.

51. Hall, J.A.S.; Maschmedt, D.J.; Biling, N.B. The Soil of Southern South Australia; The South Australian Land and Soil Book Series; Geological Survey of South Australia, Department of Water, Land and Biodiversity Conservation, Government of South Australia: Adelaide, Australia, 2009; Volume 1.

52. Youngs, E.G. Hydraulic conductivity of saturated soils. In Soil and Environmental Analysis: Physical Methods, 2nd ed.; Smith, K.A., Mullins, C.E., Eds.; Marcel Dekker, Inc.: New York, NY, USA, 2001; pp. 141-181.

53. Šimůnek, J.; van Genuchten, M.T.; Šejna, M. Recent developments and applications of the HYDRUS computer software packages. Vadose Zone J. 2016, 15, 25. [CrossRef]

54. Assouline, S.; Kamai, T.; Šimůnek, J.; Narkis, K.; Silber, A. Mitigating the impact of irrigation with effluent water: Mixing with freshwater and/or adjusting irrigation management and design. Water Resour. Res. 2020, 56, e2020WR027781. [CrossRef]

55. Oster, J.D.; Frenkel, H. The chemistry of the reclamation of sodic soils with gypsum and lime. Soil Sci. Soc. Am. J. 1980, 44, 41-45. [CrossRef]

56. Rengasamy, P.; Greene, R.S.B.; Ford, G.W.; Jordan, P.; Mehanni, A.H. Evaluation of the Gypsum Requirement of Red-Brown Earths; Research Project Series No. 192; Department of Agriculture: Victoria, Australia, 1984.

57. Singh, H.; Bajwa, M.S. Comparison of different models for describing gypsum dissolution kinetics in different aqueous salt solutions. Aust. J. Soil Res. 1990, 28, 947-953. [CrossRef]

58. Northcote, K.H.; Skene, J.K.M. Australian Soils with Saline and Sodic Properties; Soil Publication, No. 27; Commonwealth Scientific and Industrial Research Organisation: Melbourne, Australia, 1972.

59. Kelly, J.; Rangasamy, P. Diagnosis and Management of Soil Constraints: Transient Salinity, Sodicity and Alkalinity; Grain Research and Development Corporation Final Report of Project No. UA00023; University of Adelaide: Adelaide, Australia, 2006.

60. Šimůnek, J.; Šejna, M.; Saito, H.; Sakai, M.; van Genuchten, M.T. The Hydrus-1D Software Package for Simulating the Movement of Water, Heat, and Multiple Solutes in Variably Saturated Media, Version 4.17; HYDRUS Software Series 3; Department of Environmental Sciences, University of California Riverside: Riverside, CA, USA, 2013.

61. Enemark, T.; Peeters, L.J.M.; Mallants, D.; Batelaan, O. Hydrogeological conceptual model building and testing: A review. J. Hydrol. 2019, 569, 310-329. [CrossRef]

62. van Genuchten, M.T. A closed form equation for predicting the hydraulic conductivity of unsaturated soils. Soil Sci. Soc. Am. J. 1980, 44, 892-898. [CrossRef]

63. Šimůnek, J.; Suarez, D.L. Sodic soil reclamation using multicomponent transport modeling. J. Irrig. Drain. Eng. 1997, 123, 367-376. [CrossRef] 
64. Feddes, R.A.; Kowalik, P.J.; Zaradny, H. Simulation of Field Water Use and Crop Yield; Simulation Monographs: Wageningen, The Netherlands, 1978.

65. Phogat, V.; Mahadevan, M.; Skewes, M.; Cox, J.W. Modeling soil water and salt dynamics under pulsed and continuous surface drip irrigation of almond and implications of system design. Irrig. Sci. 2012, 30, 315-333. [CrossRef]

66. Phogat, V.; Skewes, M.A.; Mahadevan, M.; Cox, J.W. Evaluation of soil plant system response to pulsed drip irrigation of an almond tree under sustained stress conditions. Agric. Water Manag. 2013, 118, 1-11. [CrossRef]

67. Phogat, V.; Skewes, M.A.; McCarthy, M.G.; Cox, J.W.; Šimůnek, J.; Petrie, P.R. Evaluation of crop coefficients, water productivity, and water balance components for wine grapes irrigated at different deficit levels by a sub-surface drip. Agric. Water Manag. 2017, 180, 22-34. [CrossRef]

68. Zhang, X.; Walker, R.R.; Stevens, R.M.; Prior, L.P. Yield-salinity relationships of different grapevine (Vitis vinifera L.) scion-rootstock combinations. Aust. J. Grape Wine Res. 2002, 8, 150-156. [CrossRef]

69. Ayers, R.S.; Westcot, D.W. Water Quality for Agriculture; FAO Irrigation and Drainage Paper 29; FAO: Rome, Italy, $1985 ;$ p. 174.

70. Allen, R.G.; Pereira, L.S.; Raes, D.; Smith, M. Crop Evapotranspiration: Guidelines for Computing Crop Water Requirements; FAO Irrigation and Drainage Paper No. 56; FAO: Rome, Italy, 1998.

71. Charles, S.P.; Fu, G. Statistically Downscaled Projections for South Australia-Task 3 CSIRO Final Report; Goyder Institute for Water Research Technical Report Series No. 15/1; Goyder Institute for Water Research: Adelaide, Australia, 2015.

72. Moss, R.H.; Edmonds, J.A.; Hibbard, K.A.; Manning, M.R.; Rose, S.K.; van Vuuren, D.P.; Carter, T.R.; Emori, S.; Kainuma, M.; Kram, T.; et al. The next generation of scenarios for climate change research and assessment. Nature 2010, 463, 747-756. [CrossRef] [PubMed]

73. Phogat, V.; Cox, J.W.; Šimůnek, J. Identifying the future water and salinity risks to irrigated viticulture in the Murray-Darling Basin, South Australia. Agric. Water Manag. 2018, 201, 107-117. [CrossRef]

74. Phogat, V.; Šimůnek, J.; Skewes, M.A.; Cox, J.W.; McCarthy, M.G. Improving the estimation of evaporation by FAO-56 dual crop coefficient approach under subsurface drip. Agric. Water Manag. 2016, 178, 189-200. [CrossRef]

75. Kaledhonkar, M.J.; Tyagi, N.K.; Van Der Zee, S.E.A.T.M. Solute transport modelling in soil for irrigation field experiments with alkali water. Agric. Water Manag. 2001, 51, 153-171. [CrossRef]

76. Gonçalves, M.C.; Šimůnek, J.; Ramos, T.B.; Martins, J.C.; Neves, M.J.; Pires, F.P. Multicomponent solute transport in soil lysimeters irrigated with waters of different quality. Water Resour. Res. 2006, 42, W08401. [CrossRef]

77. Ramos, T.B.; Šimůnek, J.; Gonçalves, M.C.; Martins, J.C.; Prazeres, A.; Castanheira, N.L.; Pereira, L.S. Field evaluation of a multicomponent solute transport model in soils irrigated with saline waters. J. Hydrol. 2011, 407, 129-144. [CrossRef]

78. Shaygan, M.; Baumgartl, T.; Arnold, S.; Reading, L.P. The effect of soil physical amendments on reclamation of a saline-sodic soil: Simulation of salt leaching using HYDRUS-1D. Soil Res. 2018, 56, 829-845. [CrossRef]

79. Kaledhonkar, M.J.; Keshari, A.K.; Van Der Zee, S.E.A.T.M. Relative sensitivity of ESP profile to spatial and temporal variability in cation exchange capacity and pore water velocity under simulated field conditions. Agric. Water Manag. 2006, 83, 58-68. [CrossRef]

80. Kaledhonkar, M.J.; Sharma, D.R.; Tyagi, N.K.; Kumar, A.; Van Der Zee, S.E.A.T.M. Modeling for conjunctive use irrigation planning in sodic groundwater areas. Agric. Water Manag. 2012, 107, 14-22. [CrossRef]

81. Mosley, L.M.; Cook, F.; Fitzpatrick, R. Field trial and modelling of different strategies for remediation of soil salinity and sodicity in the Lower Murray irrigation areas. Soil Res. 2017, 55, 670-681. [CrossRef]

82. Mallants, D.; Šimůnek, J.; Torkzaban, S. Determining water quality requirements of coal seam gas produced water for sustainable irrigation. Agric. Water Manag. 2017, 189, 52-69. [CrossRef]

83. Stevens, D. Sustainable Use of Recycled Water for Horticultural Irrigation on the Northern Adelaide Plains; Final Project Report, No. VG 97081; Horticulture Australia Ltd.: Sydney, Australia, 2004.

84. Neilsen, G.H.; Stevenson, D.S.; Fitzpatrick, J.J. The effect of municipal waste-water irrigation and rate of N fertilization on petiole composition, yield and quality of Okanagan Riesling grapes. Can. J. Plant Sci. 1989, 69, 1285-1294. [CrossRef]

85. McCarthy, M.G. Irrigation of grapevines with sewage effluent. Effects on yield and petiole composition. Am. J. Enol. Vitic. 1981, 32, 189-196.

86. Paranychianakis, N.V.; Nikolantonakis, M.; Spanakis, Y.; Angelakis, A.N. The effect of recycled water on the nutrient status of Soultanina grapevines grafted on different rootstocks. Agric. Water Manag. 2006, 81, 185-198. [CrossRef]

87. United States Salinity Lab. Staff. Diagnosis and Improvement of Saline and Alkali Soils; Handbook No. 60; United States Department of Agriculture: Washington, DC, USA, 1954.

88. Fan, J.; McConkey, B.; Wang, H.; Janzen, H. Root distribution by depth for temperate agricultural crops. Field Crop. Res. 2016, 189, 68-74. [CrossRef]

89. Bower, C.A. Cation-exchange equilibria in soils affected by sodium salts. Soil Sci. 1959, 88, 32-35. [CrossRef]

90. Curtin, D.; Steppuhn, H.; Mernut, A.R.; Selles, F. Sodicity in irrigated soils in Saskatchewan: Chemistry and structural stability. Can. J. Soil Sci. 1995, 75, 17-184. [CrossRef]

91. Harron, W.R.A.; Webster, G.R.; Cairns, R.R. Relationship between exchangeable sodium and sodium adsorption ratio in a Solonetzic soil association. Can. J. Soil Sci. 1983, 63, 461-467. [CrossRef]

92. Chorom, M.; Rengasamy, P. Carbonate chemistry, $\mathrm{pH}$, and physical properties of an alkaline sodic soil as affected by various amendments. Aust. J. Soil Res. 1997, 35, 149-161. [CrossRef] 
93. Stevens, D.P.; McLaughlin, M.J.; Owens, G.; Kelly, J.; Maier, N. Agronomic issues when using reclaimed water: The Northern Adelaide Plains Experience. In Water Recycle Australia 2000; Dhillon, P., Ed.; CSIRO Land and Water: Adelaide, Australia, 2000.

94. Maas, E.V.; Hoffman, G.J. Crop salt tolerance-Current assessment. J. Irrig. Drain. 1977, 103, 115-134. [CrossRef]

95. Suarez, D.L.; Wood, J.D.; Lesch, S.M. Effect of SAR on water infiltration under a sequential rain-irrigation management system. Agric. Water Manag. 2006, 86, 150-164. [CrossRef]

96. Brady, N.C.; Weil, R.R. The Nature and Properties of Soils, 13th ed.; Prentice Hall: Upper Saddle River, NJ, USA, 2002.

97. Reading, L.; Baumgartl, T.; Bristow, K.L.; Lockington, D.A. Applying HYDRUS to flow in a sodic clay soil with solution composition dependent hydraulic conductivity. Vadose Zone J. 2012, 11, 1-10. [CrossRef]

98. Reading, L.P.; Lockington, D.A.; Bristow, K.L.; Baumgartl, T. Are we getting accurate measurements of Ksat for sodic clay soils? Agric. Water Manag. 2015, 158, 120-125. [CrossRef] 